\title{
Norepinephrine Transporter as a Target for Imaging and Therapy
}

\author{
Neeta Pandit-Taskar and Shakeel Modak \\ Memorial Sloan Kettering Cancer Center, New York, New York
}

The norepinephrine transporter (NET) is essential for norepinephrine uptake at the synaptic terminals and adrenal chromaffin cells. In neuroendocrine tumors, NET can be targeted for imaging as well as therapy. One of the most widely used theranostic agents targeting NET is metaiodobenzylguanidine (MIBG), a guanethidine analog of norepinephrine. ${ }^{123} /{ }^{131} \mid-M I B G$ theranostics have been applied in the clinical evaluation and management of neuroendocrine tumors, especially in neuroblastoma, paraganglioma, and pheochromocytoma. ${ }^{123}$ I-MIBG imaging is a mainstay in the evaluation of neuroblastoma, and ${ }^{131}$ I-MIBG has been used for the treatment of relapsed high-risk neuroblastoma for several years, however, the outcome remains suboptimal. ${ }^{131}$ I-MIBG has essentially been only palliative in paraganglioma/pheochromocytoma patients. Various techniques of improving therapeutic outcomes, such as dosimetric estimations, high-dose therapies, multiple fractionated administration and combination therapy with radiation sensitizers, chemotherapy, and other radionuclide therapies, are being evaluated. PET tracers targeting NET appear promising and may be more convenient options for the imaging and assessment after treatment. Here, we present an overview of NET as a target for theranostics; review its current role in some neuroendocrine tumors, such as neuroblastoma, paraganglioma/ pheochromocytoma, and carcinoids; and discuss approaches to improving targeting and theranostic outcomes.

Key Words: MIBG; norepinephrine transporter; neuroendocrine; neuroblastoma; ${ }^{18} \mathrm{~F}-\mathrm{MFBG}$

J Nucl Med 2017; 58:39S-53S

DOI: 10.2967/jnumed.116.186833

$\mathbf{T}$

he norepinephrine transporter (NET) is a transmembrane protein responsible for transporting norepinephrine into the synaptic terminals of the central and peripheral nervous systems as well as neuroendocrine adrenal chromaffin cells. It is encoded by the SLC6A2 gene and is crucial for the reuptake of noradrenaline; thus, it regulates noradrenergic signaling, which influences many physiologic processes, including behavior, mood, cognition, and the regulation of blood pressure and heart rate (1). The reuptake of norepinephrine is primarily driven by an active, saturable, energyand ATP-dependent process (uptake 1) and, to a lesser extent, by a passive diffusion mechanism of uptake that is nonsaturable and energy independent. After reuptake in the cell, the norepinephrine

Received Apr. 11, 2017; revision accepted Jul. 19, 2017.

For correspondence or reprints contact: Neeta Pandit-Taskar, Memorial Sloan Kettering Cancer Center, 1275 York Ave., Box 77, New York, NY 10065.

E-mail: pandit-n@mskcc.org

COPYRIGHT @ 2017 by the Society of Nuclear Medicine and Molecular Imaging. may be metabolized in mitochondria by monoamine oxidase or stored in vesicles, as facilitated by vesicular monoamine transporter 2 (2). Several malignancies of neuroendocrine origin-such as neuroblastoma, those originating from the chromaffin cells of adrenal medullary or extraadrenal paraganglionic tissue, and other cancers of sympathetic neuronal precursors - express NET, which transports norepinephrine across the cell membrane in these tumors. These cells of chromaffin origin, and therefore the tumors, show uptake, decarboxylation, and storage of monoamines and are characterized by synthesis and secretion of catecholamines (3). The NET system is therefore an attractive target for imaging and treatment. Several radiolabeled agents that use NET as a target for imaging and therapy have been developed. Several therapeutic approaches are being used, and novel methods are being explored to optimize and improve theranostic outcomes, as discussed in this article.

\section{RADIOPHARMACEUTICALS TARGETING NET MECHANISM FOR IMAGING}

Both single-photon and positron-emitting radiopharmaceuticals that target NET have been developed and used for imaging neuroendocrine tumors. The most commonly used targeting agent is the radiolabeled metaiodobenzylguanidine (MIBG) that has long been used as a theranostic for treatment of some of the neuroendocrine tumors. MIBG is a synthetic guanethidine analog of norepinephrine, initially radiolabeled with ${ }^{131} \mathrm{I}$ and used for adrenal imaging (Fig. 1) (4). The uptake is linked to NET and involves both an active (uptake 1) mechanism and a passive diffusion process (5). After uptake in the cell, a majority of MIBG remains in the cytoplasm, and the rest is stored in vesicular granules mediated by vesicular monoamine transporters (6). The uptake in the tumor is proportional to the number of neurosecretory granules (7), which may result in variable uptake and detection of tumor. MIBG radiolabeled with ${ }^{131} \mathrm{I}$ or ${ }^{123} \mathrm{I}$ has been used for targeted imaging with a $\gamma$-scanner for planar imaging and SPECT imaging, whereas ${ }^{131}$ I-MIBG has been used for therapy of neuroendocrine tumors.

\section{${ }^{123}$ //131/-MIBG for Imaging of Neuroblastoma}

Neuroblastoma is a tumor that arises from primordial neural crest cells and is predominantly seen in infants and young children. Neuroblastoma cells show high NET expression, and most neuroblastomas are MIBG-avid (Fig. 2) (8). Most of the iodine localizes intracellularly within the mitochondria, and lesser amounts are seen in the vesicles and nuclear membrane. The decay characteristics of ${ }^{131} \mathrm{I}$ - with emissions of energy that allow for penetration in the nucleus - make it suitable for therapy (9), whereas the lower $\gamma$-energy of ${ }^{123}$ I makes it a preferred isotope for imaging.

${ }^{131} \mathrm{I} /{ }^{123} \mathrm{I}-\mathrm{MIBG}$ is widely used for imaging neuroblastoma and is considered the gold standard for staging and follow-up of neuroblastoma patients $(10,11)$. Although initially ${ }^{131} \mathrm{I}-\mathrm{MIBG}$ was 


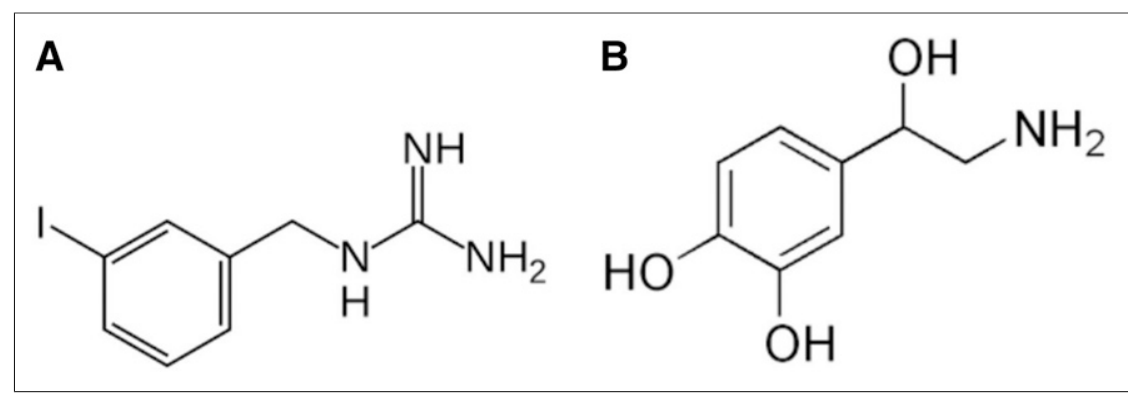

FIGURE 1. Metaiodobenylguanidine (A) and noradrenaline (B).

used for imaging, it has been replaced to a large extent by ${ }^{123} \mathrm{I}-$ MIBG, which, even though more expensive, is more favorable due to its shorter half-life and lower radiation dose that allows for higher injected activity and for superior quality of both planar and SPECT imaging.

MIBG scans have a high sensitivity for disease localization, with detection of disease in about $93 \%-97 \%$ of neuroblastoma patients, and have been recommended by the International Neuroblastoma Risk Group for evaluation of bone and bone marrow disease at initial staging and follow-up. It is more specific than MRI and has replaced bone scanning in routine evaluation (11-13). The reported sensitivity of ${ }^{123} \mathrm{I}$ - or ${ }^{131} \mathrm{I}-\mathrm{MIBG}$ for staging or recurrent neuroblastoma ranges from $76 \%$ to $100 \%$ (14-16). A prospective multicenter trial reported sensitivity of $88 \%$ and specificity of $83 \%$ for detection at diagnosis or follow-up (17). ${ }^{123} \mathrm{I}-\mathrm{MIBG}$ is reported to detect $82 \%$ of unsuspected relapses, including $27 \%$ that were otherwise undetected by other modalities (18).

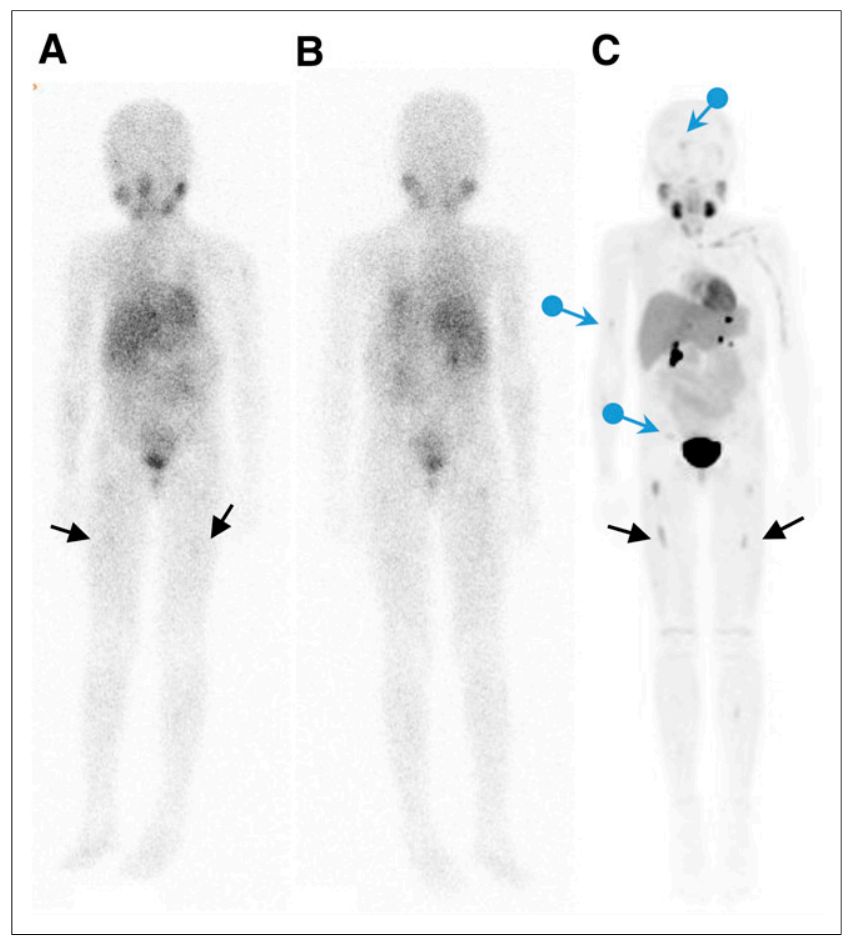

FIGURE 2. Imaging with ${ }^{123}$ I-MIBG and ${ }^{18}$ F-MFBG. ${ }^{123}$ |-MIBG wholebody anterior $(\mathrm{A})$ and posterior $(\mathrm{B})$ images show minimal uptake in bilateral femora (arrows). These lesions are better visualized on ${ }^{18} \mathrm{~F}-\mathrm{MFBG}$ $\mathrm{PET} / \mathrm{CT}$ imaging (C), which also shows additional lesions (blue arrows) not seen on ${ }^{123}$ |-MIBG imaging.
Imaging with MIBG is also prognostic and influences management in neuroblastoma. Disease extent and involvement of bone and marrow as determined by MIBG is associated with unfavorable outcome $(19,20)$. For evaluating treatment response, an early response to chemotherapy noted on MIBG scanning denotes good prognosis and correlates with both event-free survival as well as overall survival in high-risk and advanced/stage IV neuroblastoma (21). On the other hand, a lack of or incomplete response on MIBG scanning is an indicator of unfavorable outcome $(22,23)$, thereby guiding management decisions, especially in those receiving dose-intensive therapy at diagnosis. After therapy, false-negative MIBG scans may be seen in $24 \%-41 \%$ of patients probably related to changes in the NET system and trapping mechanisms caused by maturation and differentiation of tumor cells or due to the effect of chemotherapeutic agents (24-26). Imaging with ${ }^{123}$ I-MIBG is required to document uptake by tumor tissue and select patients for ${ }^{131} \mathrm{I}-\mathrm{MIBG}$ therapy. Generally a positive scan for lesion detection and good uptake in lesions would denote suitability for therapy; liver uptake serves as a good index to compare and assess suitability for therapy. Although planar imaging is easy and requires less time, SPECT allowed for improved sensitivity of detection (27) and also localization of lesions, especially with SPECT/CT. In $75 \%$ of patients, a higher number of lesions were detected with both ${ }^{131} \mathrm{I}-\mathrm{MIBG}$ and ${ }^{123} \mathrm{I}-\mathrm{MIBG}$ (28), and more soft-tissue lesions were seen in $25 \%$ of patients (29) by SPECT/CT than by planar imaging. It is recommended that stage 3 and 4 neuroblastoma patients be routinely imaged with SPECT or SPECT/CT, though it does require longer time for acquiring the scans, which may be a disadvantage in younger children, especially those requiring anesthesia for imaging.

A more comprehensive assessment of disease burden and of number and sites of disease involvement helps assess suitability for MIBG therapy. A solitary large lesion or the presence of only a few lesions involving soft tissue may be more appropriately treated with surgery, if feasible, or with localized therapy, whereas a larger number of lesions with wider distribution would benefit from treatment with ${ }^{131}$ I-MIBG. A baseline and follow-up assessment with ${ }^{123}$ I MIBG allows for assessment of the response to MIBG therapy. However, assessment of lesion changes and response by MIBG scanning is subjective and many times challenging due to the lack of quantitative measures. Semiquantitative scoring systems have been developed to provide an objective and uniform way of reporting lesions between readers $(12,30,31)$ for evaluation of disease burden and of response. The Curie scoring system, proposed by Ady et al. in 1995, assigns a score of 0-3 to 9 designated regions of the whole body; a relative score compares the posttreatment score with the pretreatment value. This method is highly reproducible, and the end of the induction score is predictive of overall response with high accuracy (30). A modified Curie scoring system also includes soft-tissue lesions and is currently widely used in multicenter trials conducted by a children's oncology group (31). A similar scoring system, proposed by the International Society of Paediatric Oncology Europe Neuroblastoma, uses a 0-6 grading scale for skeletal and soft-tissue disease (32) and is recommended by an international panel for universal routine evaluation of MIBG scanning in high-risk neuroblastoma patients (33). MIBG scoring 
has high prognostic value at diagnosis and is predictive of overall survival and event-free survival in high-risk and stage IV neuroblastoma after other systemic treatments and in assessment of disease before myeloablative therapy (34). It has shown utility in assessment of disease response to ${ }^{131} \mathrm{I}-\mathrm{MIBG}$ therapy and provides an objective criterion for assessing response and choosing patients for repeat therapies $(31,35,36)$. MIBG scoring is recommended by the International Neuroblastoma Risk Group Task Force as essential for evaluation of efficacy of therapies (12).

\section{${ }^{123} \mid{ }^{131}$ I-MIBG for Imaging of Pheochromocytoma (PHEO) and Paraganglioma (PGL)}

PHEO and PGL originate in chromaffin tissue of the adrenal medulla or sympathetic nervous system and, if functional, secrete catecholamines that lead to various symptoms. In these tumors also, MIBG uptake in cells is facilitated by NET and stored in vesicular granules facilitated by vesicular monoamine transporters. Targeted imaging of PHEO/PGL with ${ }^{131}$ I-MIBG was first evaluated in 1987 (37). Over the years, a few studies have reported variable results, with many of these studies in a small number of patients. Detection of lesions may be lower in those with low-affinity binding of MIBG to NET, lack of storage granules, or fewer NET or vesicular monoamine transporters due to cell differentiation (38). The overall sensitivity of MIBG imaging is lower for nodal disease and liver lesions, probably related to size resolution and physiologic uptake. Additionally, lower sensitivity is reported in those with familial PGL and extraadrenal disease $(39,40)$. False-negative scans are more frequent in those with the $S D H B$ mutation or von HippelLindau syndrome-associated PHEO (41), probably due to lower expression of NET. In a prospective study in 140 patients, ${ }^{123}$ IMIBG showed specificity of $82 \%$ and sensitivity of $88 \%$ for PHEO and $67 \%$ for PGL (42). Patients with multiple endocrine neoplasia syndrome may also be evaluated with ${ }^{123}$ I-MIBG to detect concurrent lesions in adrenal and thyroid glands. The detection accuracy may be improved using a lesion uptake scoring system that grades the uptake in lesion to that of liver on a $1-4$ scale (43). However, this has not been systematically evaluated for assessment of tumor burden in patients, and the role in follow-up of patients for therapy has not been studied.

\section{${ }^{123}$ / ${ }^{131}$ I-MIBG for Imaging of Carcinoids}

The ability of ${ }^{131}$ I-MIBG to target and image carcinoid tumor was initially shown in 1984 (44). The overall sensitivity for detection is low (45), with midgut tumors visualized more frequently than foregut tumors. Higher MIBG uptake is seen with higher serotonin levels (46), suggesting an uptake and storage mechanism likely similar to serotonin. Somatostatin receptor-targeted agents are more sensitive in targeting carcinoids and are preferred agents.

\section{Other NET-Targeting Tracers}

PET imaging agents targeting NET may improve detection and quantitation of disease. Benzyl guanidine analogs labeled with ${ }^{76} \mathrm{Br}-$ and ${ }^{124} \mathrm{I}-\mathrm{MIBG}$ have been developed; however, the labeling process is complex, and imaging is less optimal (47). ${ }^{124} \mathrm{I}-\mathrm{MIBG}$ imaging in neuroblastoma and PHEO/PGL $(48,49)$ is feasible; however, large studies validating its clinical use are lacking. The complex highenergy $\gamma$-emission compromises image quality and raises concern for radiation-absorbed doses; longer injection-to-imaging times and cost have limited its use. ${ }^{18} \mathrm{~F}$-fluorine-labeled analogs as substrates of NET, such as $4-{ }^{18} \mathrm{~F}$-fluoro-3-iodobenzylguanidine $(50)$ and ${ }^{18} \mathrm{~F}$ fluoropropylbenzylguanidine, have an advantage of imaging with a shorter-lived ${ }^{18} \mathrm{~F}$ isotope; however, again, there is limited clinical validation in oncology applications. In a single-patient report, ${ }^{18}$ F-fluoropropylbenzylguanidine showed biodistribution similar to that of ${ }^{123}$ I-MIBG (51). Another fluorinated guanidine analog, ${ }^{18} \mathrm{~F}$-metafluorobenzylguanidine $\left({ }^{18} \mathrm{~F}-\mathrm{MFBG}\right)$, is being evaluated in humans in a prospective study (NCT02348749). Assessment in neuroblastoma and PHEO/PGL patients showed excellent targeting of lesions, with high contrast as early as $1 \mathrm{~h}$ after injection (Fig. 2) (52). Targeted imaging of NET mechanism with fluorinelabeled PET tracer offers a more convenient single-day imaging schedule; additionally imaging with PET/MRI would be highly desirable and most suitable for pediatric patients. ${ }^{11} \mathrm{C}$-metahydroxyephedrine (HED) is a catecholamine analog (53) shown to target tumors of the sympathetic nervous system. Whole-body PET/CT with HED is feasible and safe for imaging neuroendocrine tumors (54) and provides a higher rate of detection of lesions (80/81) than ${ }^{123}$ I-MIBG (75/81); however, soft-tissue lesions in neuroblastoma patients showed less uptake, including a reported large abdominal recurrence that was better visualized by ${ }^{123}$ I-MIBG. Similarly, in a small number of patients with neuroblastoma $(n=7)$, lesion targeting with HED was seen within 5 min of administration; however, lesions in the abdomen were less well detected than with ${ }^{123}$ I-MIBG. HED shows high uptake in liver that may affect detection of lesions (55). For PHEO, a high sensitivity of $92 \%$ and a specificity of $100 \%$ have been reported in only a small series of patients. Localization of both primary and metastatic lesions including those that were MIBG negative has been noted (56). Limitations of HED are the short half-life of isotope ${ }^{11} \mathrm{C}$ (20.3 min) for imaging and inferior image quality. Patient data are lacking and, at present, the role of HED for imaging NET remains investigative. The neurotransmitter dopamine is also transported by NET and is converted by dopamine $\beta$-hydroxylase to norepinephrine in noradrenergic neurons (57). An analog of dopamine, ${ }^{18} \mathrm{~F}$-fluorodopamine $\left({ }^{18} \mathrm{~F}\right.$-FDA) has been synthesized (58) to image neuroendocrine tumors. In the neuronal vesicles, ${ }^{18} \mathrm{~F}$-FDA also is converted to ${ }^{18} \mathrm{~F}$-6-fluoronorepinephrine by dopamine $\beta$-hydroxylase or alternately metabolized by monoamine oxidase to ${ }^{18} \mathrm{~F}$-6-fluorodihydroxyphenylacetic acid in the mitochondria (59). The radiolabeling process for ${ }^{18} \mathrm{~F}-\mathrm{FDA}$ is also complex, limiting its availability and usage (60). Another PET tracer, 6- ${ }^{18}$ F-fluoro-L-dihydroxyphenylalanine ( $\left.{ }^{18} \mathrm{~F}-\mathrm{DOPA}\right)$, used to image NE tumors, does not directly target the NET but targets the catecholamine synthesis pathway. Uptake of ${ }^{18} \mathrm{~F}-\mathrm{DOPA}$ is regulated by L-amino acid decarboxylase that converts ${ }^{18} \mathrm{~F}$-DOPA to ${ }^{18} \mathrm{~F}$-FDA. Neuroendocrine cells strongly express L-amino acid decarboxylase enzyme and probably higher expression of amino acid transporters also to facilitate uptake. ${ }^{18} \mathrm{~F}-\mathrm{DOPA}$ has been radiolabeled to yield a high-specific-activity tracer (61); however, the process is long and complex, limiting its availability. Both ${ }^{18} \mathrm{~F}$-FDA and ${ }^{18} \mathrm{~F}$-DOPA have been shown to be superior to MIBG imaging for PHEO/PGL $(62,63)$, with reported sensitivity as high as $100 \%$. There is superior detection of lesions in those with hereditary neuroendocrine tumors, the $S D H B$ mutation, von Hippel-Lindau syndrome-related, and head and neck PGLs (64-66). Limited data exist for these tracers in neuroblastoma. In a small study, sensitivity and specificity of approximately $90 \%$ were reported in stage III/IV neuroblastoma patients (67), with visualization of more disease sites and better assessment of response than with ${ }^{123} \mathrm{I}$-MIBG (68). ${ }^{18} \mathrm{~F}$-DOPA lesion scores have also been evaluated, and a preliminary assessment showed a high correlation with the MIBG score (69). A higher prognostic correlation of metabolic burden detected with ${ }^{18} \mathrm{~F}$-DOPA was noted in this study. In a comparison study in 19 neuroblastoma patients 
imaged at diagnosis $(n=4)$ or at relapse $(n=15),{ }^{18} \mathrm{~F}-\mathrm{DOPA}$ had higher sensitivity $(90 \%)$ than MIBG $(\sim 56 \%)$ (70). Larger prospective and clinically focused studies are needed to establish the role for using these tracers in clinical management.

\section{NET TARGETING FOR THERAPY}

\section{3|/131|-MIBG Theranostics for Neuroblastoma}

Neuroblastoma has the ability to concentrate MIBG and is radiosensitive (71) and therefore amenable to therapy with radiolabeled ${ }^{131}$ I-MIBG. External-beam radiotherapy of widespread metastatic sites is not feasible, making systemic MIBG therapy for neuroblastoma a rational approach that has been used for several decades. MIBG therapy has usually been given to patients at relapse: both high-dose and multiple-dose strategies have been used (Fig. 3), and combined treatment with chemotherapy or biologic therapy has been studied (Table 1) $(36,72-80)$.

Initial studies demonstrated feasibility of MIBG therapy in neuroblastoma and palliation of bone pain at submyeloablative doses (81), with responses reported in about $46 \%$ of patients (82). Early phase 1 studies in chemoresistant neuroblastoma demonstrated myeloablation as a dose-limiting toxicity uniformly observed at a dose of greater than or equal to $444 \mathrm{MBq}(12 \mathrm{mCi}) / \mathrm{kg}$ (83). Severe myelosuppression, particularly a grade 4 thrombocytopenia, with the nadir occurring at about 4-6 wk, was observed at a $666 \mathrm{MBq}$ dose $(18 \mathrm{mCi}) / \mathrm{kg}(84)$. High-dose therapy, with autologous hematopoietic stem cells to reverse myeloablation, resulted in few other major toxicities, The maximum dose was primarily limited by radiation safety logistics (85). Predictors of increased marrow toxicity include whole-body or marrow-absorbed dose, extensive marrow/bone disease, prior chemotherapy treatment, and prior stem cell transplant $(84,86)$. A phase 2 study of ${ }^{131} \mathrm{I}-\mathrm{MIBG}$ therapy given at a $444-$ or $666-\mathrm{MBq}(12$ or $18 \mathrm{mCi}) / \mathrm{kg}$ dose with and without stem cell support, respectively, showed a dose-response effect; a higher response was seen with larger dose and $18 \%$ event-free survival noted at 1 y $(80)$.

Most ${ }^{131}$ I-MIBG trials have been conducted in patients with advanced neuroblastoma who have failed first-line therapy. Improvements in bone pain and objective responses have been reported at ${ }^{131} \mathrm{I}-\mathrm{MIBG}$ doses as low as $37-185 \mathrm{MBq}(1-5 \mathrm{mCi}) / \mathrm{kg}$ (81). In patients with refractory neuroblastoma, a phase 1 trial evaluated escalating doses of ${ }^{131} \mathrm{I}-\mathrm{MIBG}$. Doses greater than or equal to $444 \mathrm{MBq}(12 \mathrm{mCi}) / \mathrm{kg}$ appeared to elicit better responses than lower doses (85). In patients with refractory or relapsed neuroblastoma who were heavily prior-treated with chemotherapy, overall reported response rates to a single-agent MIBG therapy even at doses as high as $666 \mathrm{MBq}(18 \mathrm{mCi}) / \mathrm{kg}$ were only about $30 \%-40 \%$ and complete response rates were much lower. Factors influencing response include site of disease, with skeletal disease demonstrating better response than soft tissue and number of prior chemotherapeutic regimens (80). The effect of MIBG therapy on long-term survival in this group of patients remains unclear because most received further therapy after MIBG therapy $(80,87)$. In addition, patients with relapsed disease appeared to have shorter progression-free survival after MIBG therapy than those with primary refractory neuroblastoma (88).

MIBG therapy as part of induction treatment has been studied, though in fewer patients. Reasons for its limited use in this patient group include the documented chemosensitivity of the disease, logistical issues related to isolation in sick children with high disease burden at diagnosis, and prolonged thrombocytopenia after MIBG therapy that could affect further therapy. Up-front MIBG therapy appears to be safe and tolerable, again with myelosuppression being the major toxicity (89-91). With up-front treatment combined with chemotherapy, higher VGPR/CR responses were seen in those treated with doses of greater than or equal to $444 \mathrm{MBq} / \mathrm{kg}$ (12 mCi/kg) (90). In a recent pilot study, only $66 \%$ of stage 4 neuroblastoma patients could receive planned MIBG therapy (173.9-562.4 $\mathrm{MBq}$ [4.7-15.2 $\mathrm{mCi}] / \mathrm{kg}$ ). The response rate $(38 \%)$ was similar to that observed in patients with relapsed disease though prior studies on smaller groups of patients have reported higher response rates when combined with chemotherapy either before or after induction chemotherapy (91).

The causes of the relatively modest response to MIBG therapy are likely to be multifactorial (92) and have motivated consideration of strategies such as highdose or multiple-dose MIBG therapy to enhance response in refractory patients. Limitations related to radiation safety precautions and tolerability restrict the dose of MIBG that can be administered as a single dose. Thus, fractionated or split-dose therapy may be a suitable alternative. An initial study reported on the safety and feasibility of 2 MIBG doses designed to administer a whole-body dose of 4 Gy. Higher wholebody exposures were obtained when double
FIGURE 3. 12-y-old with neuroblastoma. ${ }^{123}$-MIBG pretherapy anterior (A) and posterior (B) images show multiple foci of uptake consistent with lesions in skull, right humerus, vertebrae, pelvic bones, and right tibia (arrows). These lesions are not seen in posttherapy scans ( $C$ and $D)$ obtained 8 wk after treatment with $21.8 \mathrm{GBq}(590 \mathrm{mCi})$ of ${ }^{131} \mathrm{I}-\mathrm{MIBG}$ (dose of $666 \mathrm{MBq}[18 \mathrm{mCi}] / \mathrm{kg}$ ). 


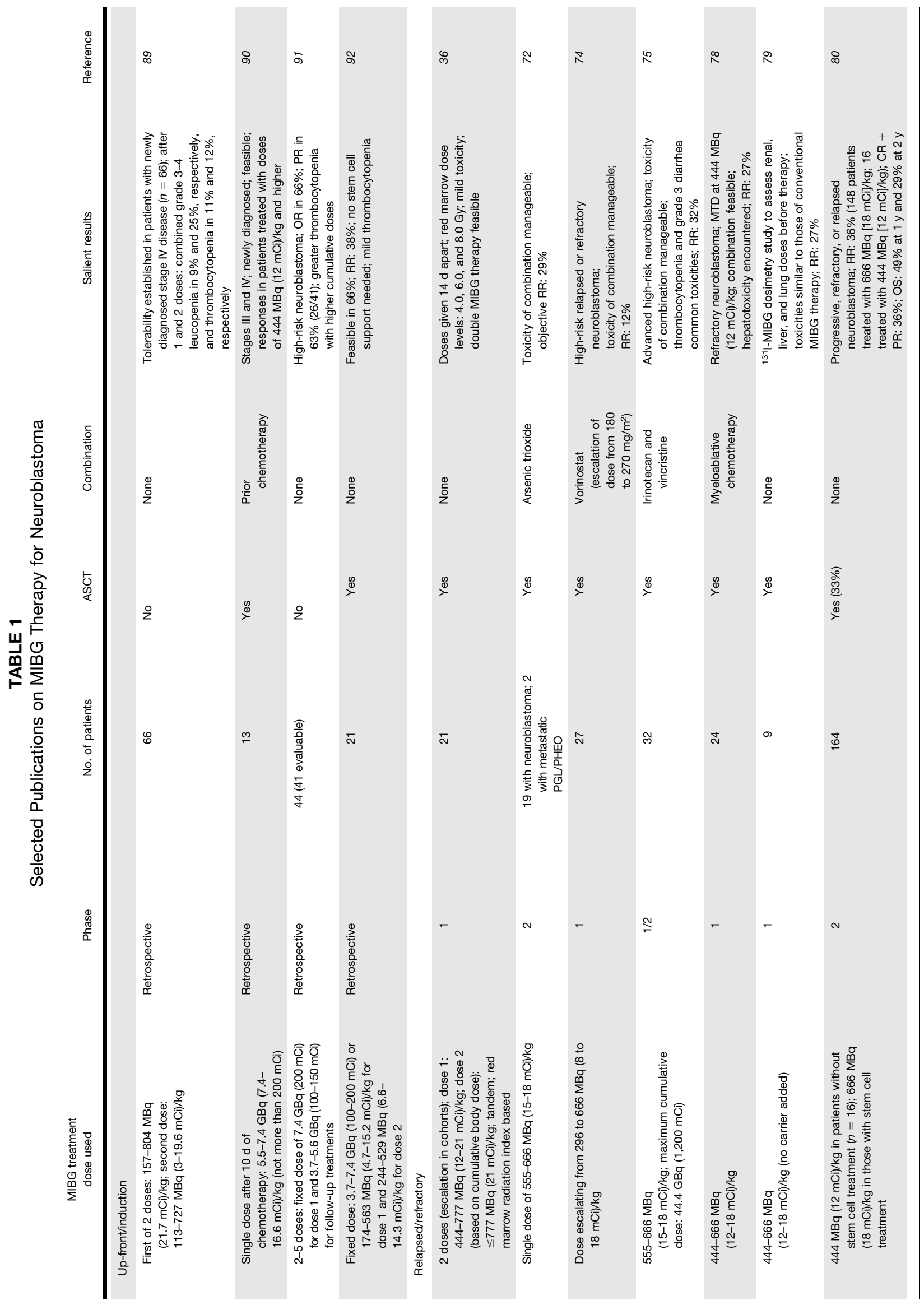




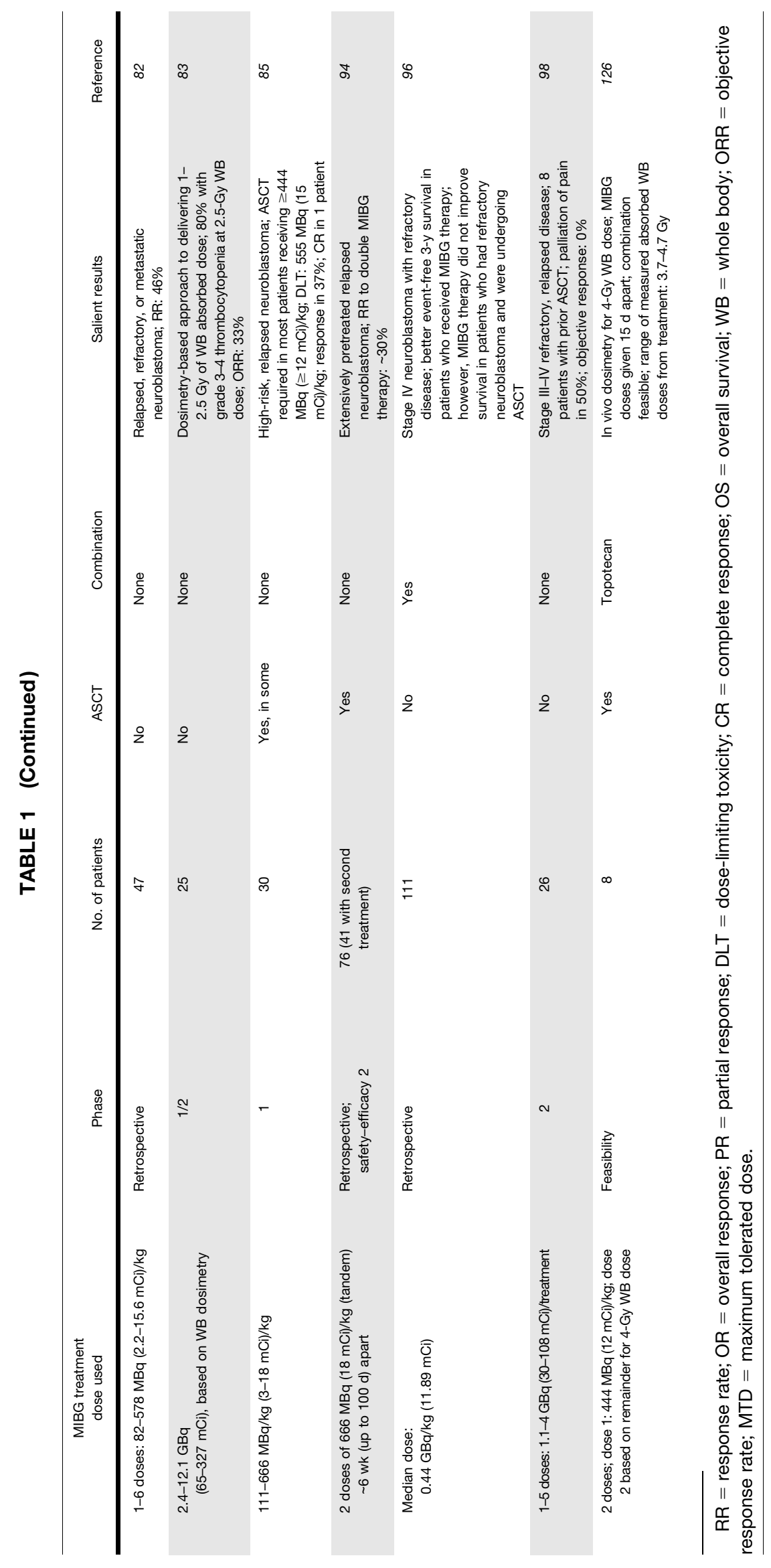

44S The Journal of Nuclear Medicine • Vol. 58 • No. 9 (Suppl. 2) • September 2017 
MIBG therapy was administered with autologous stem cell rescue after each infusion. Hematopoietic reconstitution was unaffected (36). Tandem MIBG therapy given as 2 doses, with the second dose given within 2-12 wk of the first, has also been administered safely with a single stem cell rescue after the second dose administered 42-100 d after the first. However, responses were less than $40 \%$ $(36,93)$, similar to single-dose treatments.

In patients receiving $1-5$ treatments of ${ }^{131} \mathrm{I}-\mathrm{MIBG}(2,516-5,513$ MBq [68-149 mCi] each), a 30\% objective response rate and 2\% complete response were noted. The 5-y event-free survival was $40 \%$ for stage 4 and $92 \%$ for stage 3 (94). A more recent retrospective study of 111 patients with refractory neuroblastoma noted better 3-y event-free survival for patients treated with MIBG than for those not treated with MIBG, although the results were similar to those obtained with high-dose chemotherapy and autologous stem cell transplant (ASCT) (95).

A prospective study of those receiving doses of greater than 444 $\mathrm{MBq}(12 \mathrm{mCi}) / \mathrm{kg}$ showed an overall response rate of $37 \%$, a $3 \%$ complete response, and a median survival of 6 mo (84). Multiple doses administered based on projected whole-body doses of 1, 2, or $2.5 \mathrm{~Gy}$ as estimated from diagnostic scans showed a $33 \%$ objective response rate (82). Compared with these low responses with larger and multiple doses, single-dose administrations based on body weight $(96.2-666 \mathrm{MBq}$ [2.6-18 $\mathrm{mCi}] / \mathrm{kg}$ ), whole-body dose (1-2.5 Gy), or empiric dose of 3,700-7,400 MBq (100-200 $\mathrm{mCi})$ resulted in response rates of $25 \%-46 \%(79,82,84,96)$. An early phase 2 study from multiple centers that treated patients with $1,110-3,700 \mathrm{MBq}(30-100 \mathrm{mCi})$, as a single or multiple doses, reported palliation of pain in refractory patients though no significant objective response was seen (97). Weight-based regimens have included low-activity (37-148 MBq [1-4 mCi] $/ \mathrm{kg}$ ) to highactivity (296-666 MBq [8-18 mCi]/kg) multiple dosing (Table 1). Overall, the data from many studies are heterogeneous, largely because of the retrospective nature of studies that have highly variable schema of treatments (single vs. multiple doses, low fixed dose vs. intermediate or high dose, or body-weight or whole-body dose-based treatments). Additionally, there is high variability in defining the clinical states, extent of disease, and reporting or results. The response rates and outcomes reported are highly variable across the literature (overall response, overall survival, and event-free survival). For these reasons, it is difficult to derive firm conclusions on how to best apply these therapies in routine clinical practice. Nevertheless, MIBG in refractory disease, especially with high-dose therapies and stem cell support, remains an actively pursued strategy especially for patients with chemoresistant neuroblastoma.

Most common toxicity with MIBG therapy is hematologic, which generally results in dose-dependent thrombocytopenia and is postulated to occur due to binding of MIBG to platelets (99). Other commonly observed toxicities are transient thyroid dysfunction, sialoadenitis (100), hepatic transaminitis (101), and mild acute hypertension (102). The incidence of secondary malignancy is similar to that observed in children treated with chemotherapy with a cumulative incidence of $7.6 \%$ and $14.3 \%$ at 5 and $10 \mathrm{y}$ after therapy, respectively (103). Secondary malignancies including acute nonlymphoblastic leukemia, chronic myelomonocytic leukemia, angiomatoid malignant fibrous histiocytoma, malignant schwannoma, and rhabdomyosarcoma have been reported to occur at a median of $3 \mathrm{y}(1-15 \mathrm{y})(104)$.

The role of radiosensitizers, if any, in enhancing MIBG therapy is likely to be modest but needs to be defined because radiosensitizers have additional toxicities. Such a study is currently being performed under the aegis of the Newer Advances in Neuroblastoma Therapy consortium (ClinicalTrials.gov identifier: NCT02035137). The availability of autologous hematopoietic stem cells for bone marrow rescue after high-dose MIBG therapy is limited because most patients undergo autologous bone marrow transplantation as part of the up-front therapy for high-risk neuroblastoma. The optimal use of stem cells after tandem MIBG therapy is being evaluated (ClinicalTrials.gov identifier: NCT00107289). Finally, the optimal integration of MIBG therapy into up-front treatment of high-risk neuroblastoma is unclear, but likely to be further evaluated in forthcoming studies.

\section{3|/131|-MIBG Theranostics for PHEO and PGL}

The optimal therapy for PHEO/PGL consists of surgical resection when feasible and is generally curative. In contrast, there is no standard curative therapy for metastatic disease. Most PHEO/PGLs, particularly those in cluster 2 related to the tyrosine hydroxylase signaling pathway, have a high expression of the norepinephrine transporter and concentrate ${ }^{131} \mathrm{I}$-MIBG (105), allowing for targeted therapy of disease.

${ }^{131} \mathrm{I}-\mathrm{MIBG}$ is generally given to those with progressive or symptomatic disease (Fig. 4). Systematic prospective studies with dose escalation and survival analysis are lacking, and many reported studies are in a small number of patients (Table 2). The published literature is also heterogeneous in patient selection and the reported follow-up data, which may explain differences in observed response rates and survival. The reported overall complete response rates are low, ranging from $0 \%$ to $18 \%$ (106-110).

Individual doses of ${ }^{131} \mathrm{I}-\mathrm{MIBG}$ used for therapy in published studies are highly variable, ranging from low $(2,960 \mathrm{MBq}$ [80 $\mathrm{mCi}]$ to less than or equal to $7,400 \mathrm{MBq}$ [200 $\mathrm{mCi}]$ ), intermediate (up to $18,500 \mathrm{MBq}[500 \mathrm{mCi}])$, to high doses of ${ }^{131} \mathrm{I}-\mathrm{MIBG}$ that are often weight-based (444-666 MBq [12-18 mCi]/kg) (107-109,111). Most common treatment schemas used are multiple, low doses of MIBG therapy typically administered every 3-6 mo, primarily with a palliative rather than curative intent. Formal phase 1 or optimal dose-finding studies are lacking in PHEO/PGL patients and most reports are from retrospective studies. In general, doses below $11.1 \mathrm{GBq}(300 \mathrm{mCi})$ are well tolerated without severe myelosuppression. Acute adverse events are transient and consist of mild to moderate nausea, vomiting, and hypertension (112). The most common subacute toxicity is myelosuppression, with thrombocytopenia being more common than neutropenia. Myelosuppression is much less common as patients may have received little to no prior chemotherapy. ${ }^{131}$ I-MIBG doses with a weightbased dose of greater than 2 Gy caused a higher number of grade 3 or 4 hematologic toxicity (107). Biochemical hypothyroidism has been reported in $11 \%-20 \%$ despite thyroid blockade with potassium iodide but symptomatic hypothyroidism is rare (113). Those receiving high single doses of MIBG therapy have a higher incidence of toxicities. In a phase 2 study in 50 patients with $\mathrm{PHEO} / \mathrm{PGL}$ receiving ${ }^{131} \mathrm{I}-\mathrm{MIBG}$ doses ranging from 18.2 to $42.9 \mathrm{GBq}(492-1,160 \mathrm{mCi})$, greater than or equal to grade 2 neutropenia and thrombocytopenia were observed in $87 \%$ and $83 \%$ of patients, respectively (108). Rare pulmonary toxicities, such as adult respiratory distress syndrome, can occur, and an increased risk is noted in those who have proteinuria.

Overall, MIBG therapy has demonstrated clinical responses in patients with PHEO/PGL. However, although objective responses are common, complete response rates are exceedingly low $(<5 \%$ in a large retrospective review) (106). Furthermore, there is a wide 


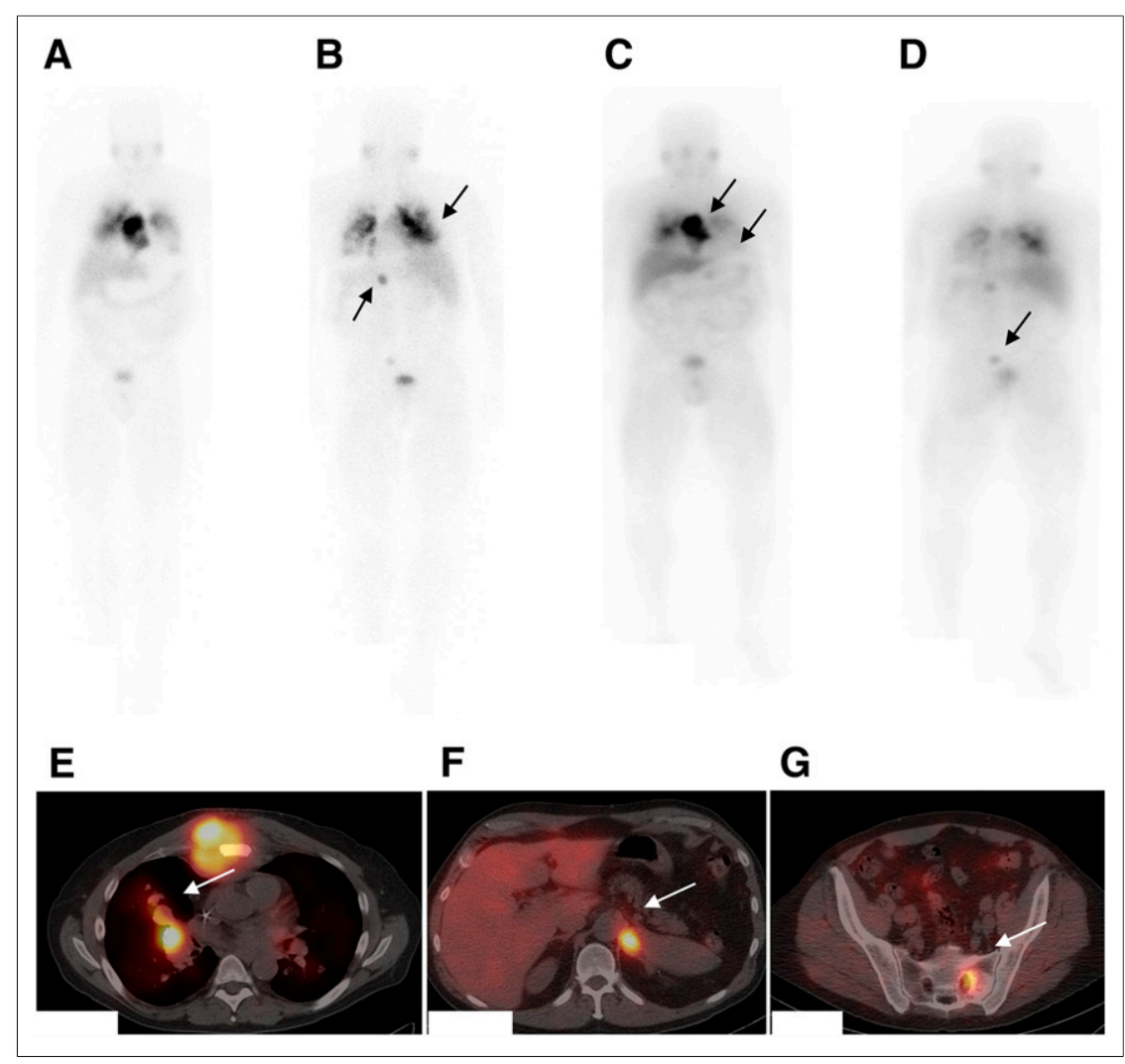

FIGURE 4. Patient with metastatic pheochromocytoma presented with progression of disease. 123I-MIBG pretherapy anterior (A) and posterior (B) images show increased uptake in bilateral lung lesions and intense uptake in large sternal lesion, left adrenal lesion, and sacral lesion (arrows). Patient was eligible for ${ }^{131} \mathrm{I}-\mathrm{MIBG}$ and was treated with approximately $8,510 \mathrm{MBq}(230 \mathrm{mCi})$ of 131I-MIBG. (C-G) Posttherapy planar anterior (C) and posterior (D) scans and SPECT/CT fused images at 3 levels (E-G) show good targeting of lesions (arrows). Plasma normetanephrine and total metanephrine levels decreased from greater than 20,000 and $40,000 \mathrm{pg} / \mathrm{mL}$, respectively, at baseline to 14,295 and $14,329 \mathrm{pg} / \mathrm{mL}$, respectively, at $13 \mathrm{wk}$ after treatment.

variation in response rates in reported studies. These differences are probably related to patient selection, biologic factors such as NET expression, dose and frequency of MIBG administrations, and length of follow-up. Reported objective response rates are typically less than $50 \%$. A metaanalysis of 17 studies involving 243 patients reporting a response rate of $27 \%$. Rates of symptom control and hormonal responses are typically higher than objective responses (114). There does not appear to be a clear dose-response effect of MIBG therapy. The quality of responses has been associated with the subtype of disease (better responses in PGL than in PHEO) (114) and sites of disease (better responses in soft tissues vs. bone). An objective response to the initial dose of MIBG therapy appeared to be associated with a favorable prognosis in patients receiving multiple doses (115).

The impact of MIBG therapy on overall survival is hard to assess because PHEO/PGL even when malignant is an indolent disease, and patients often survive for more than $10 \mathrm{y}$ without any anticancer therapy. In a retrospective study of 33 patients, responders and patients receiving doses of greater than $18.5 \mathrm{GBq}$ $(500 \mathrm{mCi})$ appeared to have better survival rates than nonresponders and those receiving doses of less than $18.5 \mathrm{GBq}(500 \mathrm{mCi})(111)$.

At present, the general approach to administering MIBG therapy is giving multiple fractionated low or intermediate doses without the need for autologous stem cell rescue. Multiple doses at intervals of $8-12$ wk may be administered with the intention of stabilization of disease or symptoms. MIBG has an established role in symptom relief and palliation; improvement in disease-associated pain and symptoms related to catecholamine excess has been reported in $50 \%-85 \%$ of patients $(111,116)$. However, robust and durable objective and clinical responses are rare, with few complete responses. ${ }^{131} \mathrm{I}-\mathrm{MIBG}$ therapy is therefore not curative. Although symptomatic relief and partial responses may be achieved, the survival benefit and efficacy have not been conclusively proven. There is no universal consensus on ${ }^{131} \mathrm{I}-\mathrm{MIBG}$ treatment schemas or doses for maximizing benefit. ${ }^{131} \mathrm{I}-\mathrm{MIBG}$ therapy has no significant role in certain specific biologic subtypes of malignant PHEO/PGL such as those with the $S D H B$ mutation due to lack of significant uptake and false-negative results (110). The role of the combination of MIBG with other targeted therapies has not been studied and needs to be evaluated.

In carcinoids, good symptomatic relief and control of disease at cumulative doses ranging from $1,850 \mathrm{MBq}(50 \mathrm{mCi})$ to more than $74 \mathrm{GBq}(2 \mathrm{Ci})$ as well as in single or multiple doses of less than $7,400 \mathrm{MBq}$ (200 $\mathrm{mCi}$ ) have been noted with ${ }^{131}$ I-MIBG therapy (117). The role of high-dose therapy has not been evaluated. Objective response rates are reported in up to $30 \%$ of patients, symptomatic responses are reported in $38 \%-92 \%$, and biochemical responses are reported in about $13 \%-73 \%$ patients; complete responses are rare (118-120). Again, due to the high variation in the performance of studies and reported outcomes, the assessment of survival benefit is limited. Median 5-y survival is reported as $42 \%-78 \%(119,120)$. Longer survival has been noted in those treated with larger single treatment with greater than $14.8 \mathrm{GBq}(400 \mathrm{mCi})(4.69 \mathrm{y}$ vs. $1.86 \mathrm{y})$ and in those with symptomatic response and biochemical improvement as against those without. At present, because of the higher avidity of somatostatin receptor-directed agents, MIBG therapy is generally not used.

\section{STRATEGIES FOR IMPROVING NET TARGETING AND DOSE DELIVERY WITH ${ }^{131}$ I-MIBG FOR THERAPY}

\section{High-Specific-Activity 123/131/-MIBG}

The process of uptake of MIBG is saturable, hence conventional MIBG preparation containing high proportions of noniodinated MIBG molecules could saturate binding sites and reduce the antitumor effect of MIBG therapy. High-specific-activity non-carrier-added ${ }^{123} \mathrm{I} /{ }^{131} \mathrm{I}-\mathrm{MIBG}$ concentrates in higher amounts in tumor cells (121) and thus has the potential to be more effective as a targeting agent. Specific activities of greater than $44.4 \mathrm{GBq}(1,200 \mathrm{mCi}) / \mu \mathrm{mol}$ for ${ }^{123} \mathrm{I}-\mathrm{MIBG}$ and more than $59.2 \mathrm{GBq}(1,600 \mathrm{mCi}) / \mu \mathrm{mol}$ for ${ }^{131}$ I-MIBG can be obtained using an efficient method of radiolabeling (Ultratrace; Molecular Insight Pharmaceuticals, Inc.) 


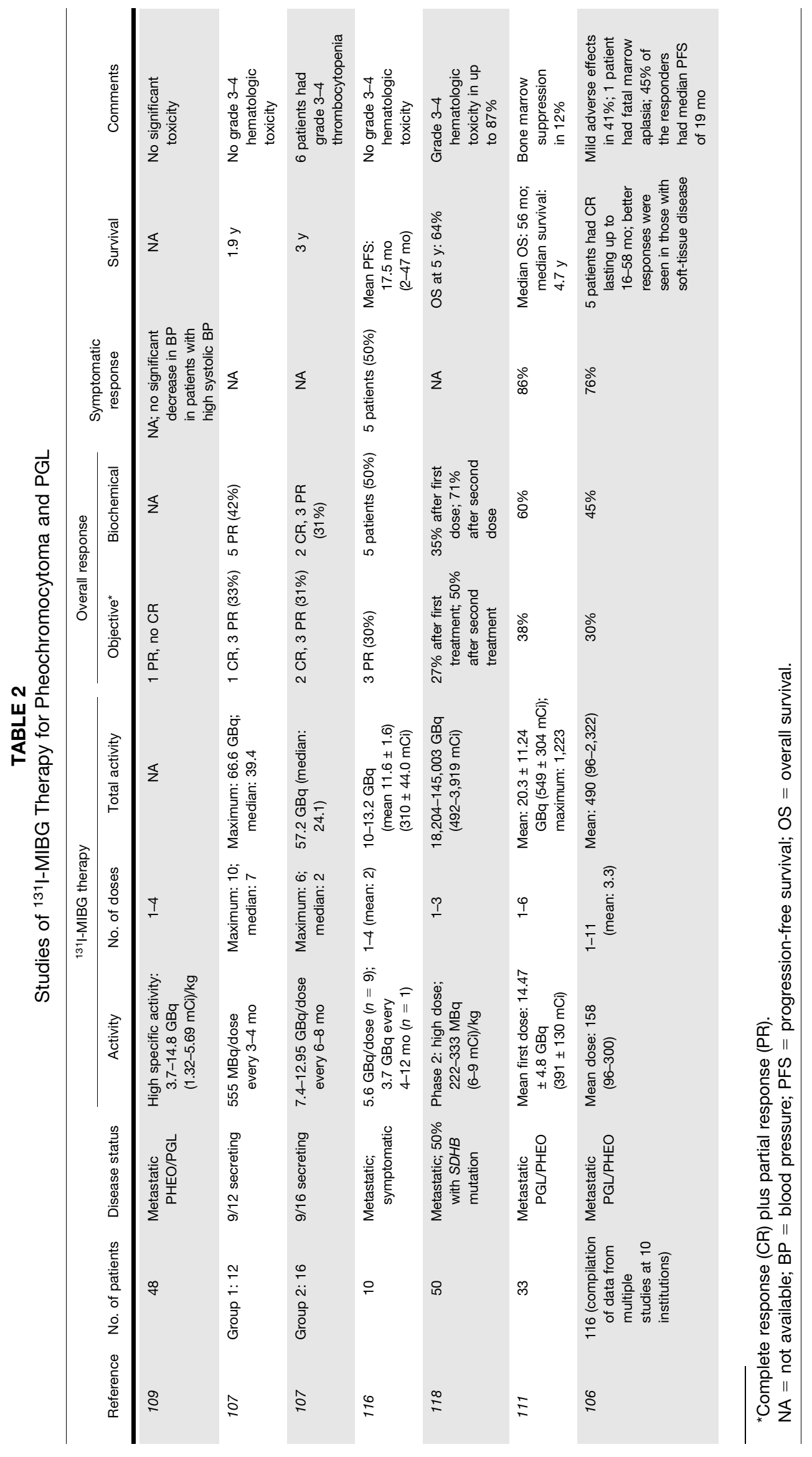


(122). A phase 1 study of non-carrier-added ${ }^{123}$ I-MIBG showed favorable dosimetry and safety. A higher contrast was noted for uptake in the heart and slightly larger activity noted in the gastrointestinal tract compared with conventional ${ }^{123}$ I-MIBG (123). At present, limited data exist regarding efficacy, and distinct clinical advantage of high-specific-activity MIBG has not been proven, though a lower incidence of side effects, such as nausea, vomiting, and hypertension, has been reported for both neuroblastoma and PHEO/PGL patients for imaging and therapy $(109,124)$. In a phase 1 clinical trial with non-carrier-added MIBG in patients with high-risk neuroblastoma at doses of 444, 555, or $666 \mathrm{MBq}(12,15$, or $18 \mathrm{mCi}$, respectively)/kg, no dose-limiting toxicities occurred; however, response rates were similar to those observed with conventional MIBG therapy (79). More data are needed to establish its advantage over regular MIBG for therapeutic use. A phase 2 trial of Ultratrace ${ }^{131}$ I-Iobenguane (Molecular Insight Pharmaceuticals, Inc.) in PHEO/PGL patients is ongoing (NCT00874614).

Dosimetry and Treatment Planning. Dosimetric estimations allow for maximizing activity administration while keeping normal organ doses within tolerable limits, thereby preventing prohibitive toxicity. For neuroblastoma, the treatments with ${ }^{131}$ I-MIBG have mostly been based on empiric dosing ranging commonly between 3,700 and 7,400 $\mathrm{MBq}(100-200 \mathrm{mCi})$ per dose repeated at $4 \mathrm{wk}$ induction (91), or $\mathrm{MBq}(\mathrm{mCi}) / \mathrm{body}$ weight using 96.2-666 MBq (2.6 to $18 \mathrm{mCi}) / \mathrm{kg}$ dose $(82,85,95,125)$. Studies that have included dosimetric estimations have mainly assessed whole-body radiation doses or red marrow absorbed-dose estimates to plan therapeutic doses (126). Estimates from pretherapy imaging with ${ }^{123} \mathrm{I} /{ }^{131} \mathrm{I}$-MIBG imaging may vary between $20 \%$ and $30 \%$ from the actual doses calculated from posttherapy imaging (127) and may result in underdosing in about $65 \%$ of patients $(82,128-130)$. Large intrapatient variations have been noted when a whole-body absorbed dose approach was used (129) that may not correlate with the response or toxicity (131). Very few studies have actually given therapy based on estimated tumor dosimetry. Estimated doses to the tumor tissue for weight and whole-body-based treatment doses have ranged between 10 and 103 Gy (129) in neuroblastoma and between 0.27 and $1.08 \mathrm{cGy} / \mathrm{Mbq}(10$ and $40 \mathrm{cGy} / \mathrm{mCi})$ in PHEO/PGL $(132,133)$. Optimal predictive dose to tumor that would lead to tumor responses is not known. For tandem high-dose therapies, normal organ doses become more relevant as compared with the bone marrow dose, as stem cell support can be given for marrow toxicity. Serial ${ }^{131}$ I-MIBG scanning-based organ dose estimates are conservative and may be used to plan the dose for second therapy with ${ }^{131}$ I-MIBG (134).

Quantitative PET imaging would allow for superior organ and lesion dosimetry. Radiolabeled ${ }^{124} \mathrm{I}-\mathrm{MIBG}$, with a physical halflife of $4.2 \mathrm{~d}$ for ${ }^{124} \mathrm{I}$ decay, allows for multiple-day imaging and has been used for dosimetric estimates. Pretherapeutic imaging to estimate disease distribution and burden is possible with high sensitivity in both neuroblastoma and PHEO patients $(48,49)$. Radiation dosimetry predicted from animal data was favorable, with mean effective doses ranging from $0.34 \mathrm{mSv} / \mathrm{MBq}$ for adults to 1.9-3.75 for children 1 y old or younger (135). In a preclinical xenograft model for neuroblastoma, the radiation dose in tumors and organs was determined. It was estimated that 52.8-206 MBq of ${ }^{131}$ I-MIBG would deliver $20 \mathrm{~Gy}$ to tumors (137). An early study in a small number of patients showed the feasibility of estimating lesion doses and estimated tumor doses in the range of 3-7.5 Gy with ${ }^{131} \mathrm{I}-\mathrm{MIBG}$ treatment doses ranging up to $11 \mathrm{GBq}$ (137). The feasibility of dose estimations has been shown; however, the clinical assessment in systematic studies is lacking. A phase $1 / 2$ study in patients with neuroblastoma to assess safety and compare lesion detection with ${ }^{123}$ I-MIBG is under way (NCT02043899). A PET tracer for routine use for dosimetric evaluation has not been validated.

\section{Use of a-Emitter for NET Targeting}

To increase the cytocidal effect, an $\alpha$-emitter with high linear energy transfer within a short range of 50-80 $\mu \mathrm{m}$ would potentially be advantageous in smaller tumors. It can also cause bystander effect in regions of specific uptake with limited radiation to adjacent normal tissues, due to its short path length, resulting in lower side effects. ${ }^{211} \mathrm{At}$ is a long lived $\alpha$-emitter with a half-life of $7.2 \mathrm{~h}$ that has been used to label MIBG analogs: ${ }^{211}$ At-metaastatobenzylguanidine (MABG) and ${ }^{211}$ At-astatofluorobenzylguanidine have been developed (138). A kit method for labeling has also been developed that allows for more convenient and easy utilization (139). MABG showed high specific binding in vitro (140) and high uptake in tumor cells in mice (141). In cell cultures, MABG showed dose-dependent toxicity at low level radiation but elimination of cytotoxicity at high levels (142). Given the physical characteristics, it is expected to be effective treatment, however, clinical studies with MABG as a therapeutic are lacking. Feasibility of use in patients, dosage, and effects are yet to be evaluated and established.

\section{Combination Therapy with NET-Targeting Agents with Radiosensitizers or Chemotherapeutic Agents}

A further approach to enhance NET-directed MIBG therapy involves its combination with radiosensitizers. Preclinical mechanistic justifications for such a combination include enhancement of NET expression or activity, for example, by vorinostat (143); synergistic effect on inhibition of radiation-induced DNA repair, for example, by topoisomerase inhibitors (144); and synergistic elicitation of autophagy and apoptosis, for example, by arsenic trioxide (145). Cisplatin pretreatment may also enhance expression of NET and MIBG uptake (146). Coadministration with poly (adenosine diphosphate) ribose polymerase induced increased DNA damage in xenografts (147). Histone deacetylase inhibitors act by derepressing gene-encoded proteins, such as caspaze-8, essential for apoptosis. Vorinostat, a histone deacetylase inhibitor, has been noted to increase NET expression and uptake of ${ }^{123}$ I-MIBG in xenografts (143). These observations led to the clinical testing of MIBG therapy in combination with radiosensitizers.

Early-phase studies have demonstrated that high-dose MIBG therapy administered in conjunction with the topoisomerase inhibitors topotecan and irinotecan (126), the histone deacetylase inhibitor vorinostat (74), and arsenic trioxide (72) is safe and tolerable in neuroblastoma with a modest increase in additional toxicities. However, in the heterogeneous groups of patients studied, there did not appear to be a marked improvement in response rates. ${ }^{131} \mathrm{I}-\mathrm{MIBG}$ plus arsenic trioxide in neuroblastoma was well tolerated, with an adverse event profile similar to that of ${ }^{131} \mathrm{I}-\mathrm{MIBG}$ therapy alone. The addition of arsenic trioxide to ${ }^{131} \mathrm{I}-\mathrm{MIBG}$ did not significantly improve response rates compared with historical data therapy only (72). For high-risk neuroblastoma, a New Approaches to Neuroblastoma Therapy study showed feasibility of treatment with ${ }^{131} \mathrm{I}-\mathrm{MIBG}$ in combination with CEM regimen (carboplatin, etoposide, and melphalan) and ASCT in 50 patients. A $10 \%$ response was noted (complete response and partial response) in those with primary refractory or progressive disease (148). A comparative study of MIBG therapy alone, MIBG combined with vincristine 
and irinotecan, and MIBG with only vorinostat is ongoing (NCT02035137); MIBG with vorinostat in resistant or relapsed neuroblastoma has been evaluated (NCT010119850). Further investigations are under way to determine whether radiation sensitizers can indeed enhance the therapeutic effect of radioiodinated MIBG; this would be most applicable to refractory and advanced neuroblastoma.

Experience with combined chemotherapy and ${ }^{131} \mathrm{I}-\mathrm{MIBG}$ therapy is limited in PHEO but feasible. In a small study, whole-body dosimetry-based treatment to deliver 85-90 cGy per administration was given with cyclophosphamide-vincristine-dacarbazine chemotherapy (149). Hematologic toxicity limits dosing and requires reduction of chemotherapy in some patients (150). In hereditary PGL/PHEO syndrome with $S D H B$ mutation patients, combination of ${ }^{131} \mathrm{I}-\mathrm{MIBG}$ and sunitinib resulted in a significant response (151).

\section{Combination Therapy with NET-Targeting Agents and Other Radiopharmaceuticals}

Use of ${ }^{131} \mathrm{I}-\mathrm{MIBG}$ with somatostatin-targeting agents in nonneuroblastoma neuroendocrine tumors is being evaluated (NCT01099228). Patient groups are receiving either ${ }^{131} \mathrm{I}-\mathrm{MIBG}$ and ${ }^{90} \mathrm{Y}$-DOTATOC or ${ }^{131}$ I-MIBG and ${ }^{177} \mathrm{Lu}$-DOTATATE. The different targets for the 2 radiopharmaceuticals and organ distribution may allow for more tumor dosing while limiting organ toxicity. Theoretic modeling showed increased tumor doses and tumor-to-critical-organ dose ratio; maximum combined therapy tumor dose increased $68 \%$ for a tumor dose ratio of 2.57 , using $92 \%$ of the maximum tolerated ${ }^{90}$ Y-DOTATOC activity supplemented with $76 \%$ of the maximum tolerated activity of ${ }^{131} \mathrm{I}-\mathrm{MIBG}$. Variations in organ radiationabsorbed dose/MBq and dose-limiting values altered both the magnitude of the increase and the range at which combinedagent therapy was advantageous (152).

\section{Localized Therapy}

Injection of the radiopharmaceutical to deliver the agent directly or selectively to the lesions from a localized delivery technique enables administration of higher radiation dose to the site of tumor while minimizing systemic side effects. Intraarterial injection of ${ }^{131}$ I-MIBG has been used to treat liver metastases or primary tumors from neuroendocrine tumors (153). In a small study $(n=17),{ }^{131} \mathrm{I}-$ MIBG injected via the hepatic artery or superior mesenteric artery/ ileocolic artery/lumbar branch delivered a $69 \%$ higher dose to tumor (154). No systematic studies have been conducted to further evaluate the approach for effectiveness or efficacy. The invasive nature of this approach and availability of other localized techniques of therapy for liver metastasis have probably limited wider use. Similar localized approaches with MABG or combined therapeutic agents have not been evaluated.

\section{Novel Techniques for Targeting NET: Reporter Systems}

NET may serve as a reporter gene for noninvasive imaging of genetically modified cells using radiolabeled targeting agents. Availability of existing radiolabeled agents for imaging the specific expression of NET makes this an attractive probe. Retroviral transfection of the human NET gene can enhance uptake of MIBG (155). ${ }^{131}$ I-MIBG imaging of transduced cells showed 66- to 120-times-higher uptake, compared with parental cells, that was highly specific and NET driven (156). ${ }^{11} \mathrm{C}-m$-hydroxyephedrine as a PET imaging probe for imaging gene therapy has been explored; the short life of the isotope is, however, limiting (157). Subsequent modifications to this approach have included linking to fluorescent dye by constructing an internal ribosomal entry site linked hybrid
NET and green fluorescent protein reporter gene that allowed for imaging with ${ }^{124}$ I-MIBG PET as well as fluorescence optical imaging (158). Transfected viruses with NET reporter genes may allow for imaging and targeting of a variety of tumors and are currently being explored in vitro and in xenografts (159). Highly sensitive imaging of $\mathrm{T}$ cells has been performed in xenografts using a PET tracer ${ }^{18} \mathrm{~F}-\mathrm{MFBG}-$ human NET reporter probe (160).

\section{CONCLUSION}

NET is an attractive theranostic target. The imaging of NET with MIBG plays an intricate role in the management of neuroendocrine malignancies and is a mainstay in the evaluation and follow-up of neuroblastoma. Therapeutic targeting of NET allows for treatment options in advanced and refractory neuroblastoma. For other neuroendocrine tumors, NET-targeting MIBG therapy is an option; however, this may be superseded by other receptor-targeting agents. Novel methods for improving therapeutic options with NET targeting using radiolabeled MIBG are being explored, but systematic trials are needed for clinical validation and defining routine use in specific clinical stages. Novel methods of targeting NET that may expand the application of targeted theranostics with NET are being developed.

\section{DISCLOSURE}

This research was funded in part through National Cancer Institute Cancer Center Support Grant P30 CA008748. No other potential conflict of interest relevant to this article was reported.

\section{REFERENCES}

1. Stöber G, Nöthen MM, Pörzgen P, et al. Systematic search for variation in the human norepinephrine transporter gene: identification of five naturally occurring missense mutations and study of association with major psychiatric disorders. Am J Med Genet. 1996;67:523-532.

2. Mandela P, Ordway GA. The norepinephrine transporter and its regulation. J Neurochem. 2006;97:310-333.

3. Höpfner M, Sutter AP, Beck NI, et al. Meta-iodobenzylguanidine induces growth inhibition and apoptosis of neuroendocrine gastrointestinal tumor cells. Int $J$ Cancer. 2002;101:210-216.

4. Wieland DM, Swanson DP, Brown LE, Beierwaltes WH. Imaging the adrenalmedulla with an I-131-labeled antiadrenergic agent. J Nucl Med. 1979;20:155158.

5. Lashford LS, Hancock JP, Kemshead JT. Meta-iodobenzylguanidine (mIBG) uptake and storage in the human neuroblastoma cell line SK-N-BE(2C). Int J Cancer. 1991;47:105-109.

6. Kölby L, Bernhardt P, Levin-Jakobsen AM, et al. Uptake of meta-iodobenzylguanidine in neuroendocrine tumours is mediated by vesicular monoamine transporters. $\mathrm{Br} \mathrm{J}$ Cancer. 2003;89:1383-1388.

7. Bomanji J, Levison DA, Flatman WD, et al. Uptake of iodine-123 MIBG by pheochromocytomas, paragangliomas, and neuroblastomas: a histopathological comparison. J Nucl Med. 1987;28:973-978.

8. Dubois SG, Geier E, Batra V, et al. Evaluation of norepinephrine transporter expression and metaiodobenzylguanidine avidity in neuroblastoma: a report from the Children's Oncology Group. Int J Mol Imaging. 2012;2012:250834.

9. Gaze MN, Huxham IM, Mairs RJ, Barrett A. Intracellular localization of metaiodobenzyl guanidine in human neuroblastoma cells by electron spectroscopic imaging. Int J Cancer. 1991;47:875-880.

10. Kushner BH, Cheung NK. Exploiting the MIBG-avidity of neuroblastoma for staging and treatment. Pediatr Blood Cancer. 2006;47:863-864.

11. Brisse HJ, McCarville MB, Granata C, et al. Guidelines for imaging and staging of neuroblastic tumors: consensus report from the International Neuroblastoma Risk Group Project. Radiology. 2011;261:243-257.

12. Matthay KK, Shulkin B, Ladenstein R, et al. Criteria for evaluation of disease extent by ${ }^{123}$ I-metaiodobenzylguanidine scans in neuroblastoma: a report for the International Neuroblastoma Risk Group (INRG) Task Force. Br J Cancer. 2010;102:1319-1326. 
13. Monclair T, Brodeur GM, Ambros PF, et al. The International Neuroblastoma Risk Group (INRG) staging system: an INRG Task Force report. J Clin Oncol. 2009;27:298-303.

14. Boubaker A, Bischof Delaloye A. MIBG scintigraphy for the diagnosis and follow-up of children with neuroblastoma. Q J Nucl Med Mol Imaging. 2008; 52:388-402.

15. Rufini V, Fisher GA, Shulkin BL, Sisson JC, Shapiro B. Iodine-123-MIBG imaging of neuroblastoma: utility of SPECT and delayed imaging. J Nucl Med. 1996;37:1464-1468

16. Jacobson AF, Deng H, Lombard J, Lessig HJ, Black RR. ${ }^{123}$ I-meta-iodobenzylguanidine scintigraphy for the detection of neuroblastoma and pheochromocytoma: results of a meta-analysis. J Clin Endocrinol Metab. 2010;95:2596-2606.

17. Vik TA, Pfluger T, Kadota R, et al. ${ }^{123}$ I-mIBG scintigraphy in patients with known or suspected neuroblastoma: results from a prospective multicenter trial. Pediatr Blood Cancer. 2009;52:784-790.

18. Kushner BH, Kramer K, Modak S, Cheung NK. Sensitivity of surveillance studies for detecting asymptomatic and unsuspected relapse of high-risk neuroblastoma. J Clin Oncol. 2009;27:1041-1046.

19. Labreveux de Cervens C, Hartmann O, Bonnin F, et al. What is the prognostic value of osteomedullary uptake on MIBG scan in neuroblastoma patients under one year of age? Med Pediatr Oncol. 1994;22:107-114.

20. Schmidt M, Simon T, Hero B, Schicha H, Berthold F. The prognostic impact of functional imaging with ${ }^{123} \mathrm{I}-\mathrm{mIBG}$ in patients with stage 4 neuroblastoma $>1$ year of age on a high-risk treatment protocol: results of the German Neuroblastoma Trial NB97. Eur J Cancer. 2008;44:1552-1558.

21. Matthay KK, Edeline V, Lumbroso J, et al. Correlation of early metastatic response by ${ }^{123}$ I-metaiodobenzylguanidine scintigraphy with overall response and event-free survival in stage IV neuroblastoma. J Clin Oncol. 2003;21: 2486-2491.

22. Katzenstein HM, Cohn SL, Shore RM, et al. Scintigraphic response by ${ }^{123}$ Imetaiodobenzylguanidine scan correlates with event-free survival in high-risk neuroblastoma. J Clin Oncol. 2004;22:3909-3915.

23. Papathanasiou ND, Gaze MN, Sullivan K, et al. ${ }^{18}$ F-FDG PET/CT and ${ }^{123}$ Imetaiodobenzylguanidine imaging in high-risk neuroblastoma: diagnostic comparison and survival analysis. J Nucl Med. 2011;52:519-525.

24. Troncone L, Rufini V, Danza FM, et al. Radioiodinated metaiodobenzylguanidine (*I-MIBG) scintigraphy in neuroblastoma: a review of 160 studies. $J$ Nucl Med Allied Sci. 1990;34:279-288.

25. Feine U, Müller-Schauenburg W, Treuner J, Klingebiel T. Metaiodobenzylguanidine (MIBG) labeled with ${ }^{123} \mathrm{I} /{ }^{131} \mathrm{I}$ in neuroblastoma diagnosis and follow-up treatment with a review of the diagnostic results of the International Workshop of Pediatric Oncology held in Rome, September 1986. Med Pediatr Oncol. 1987;15:181-187.

26. Kushner BH, Yeh SD, Kramer K, Larson SM, Cheung NK. Impact of metaiodobenzylguanidine scintigraphy on assessing response of high-risk neuroblastoma to dose-intensive induction chemotherapy. J Clin Oncol. 2003;21:1082-1086.

27. Rufini V, Giordano A, Di Giuda D, et al. $\left[{ }^{123} \mathrm{I}\right] \mathrm{MIBG}$ scintigraphy in neuroblastoma: a comparison between planar and SPECT imaging. Q J Nucl Med. 1995;39(suppl 1):25-28.

28. Fukuoka M, Taki J, Mochizuki T, Kinuya S. Comparison of diagnostic value of I-123 MIBG and high-dose I-131 MIBG scintigraphy including incremental value of SPECT/CT over planar image in patients with malignant pheochromocytoma/paraganglioma and neuroblastoma. Clin Nucl Med. 2011; 36:1-7.

29. Černý I, Prášek J, Kašpárková H. Superiority of SPECT/CT over planar ${ }^{123}$ ImIBG images in neuroblastoma patients with impact on Curie and SIOPEN score values. Nuklearmedizin. 2016;55;151-157.

30. Ady N, Zucker JM, Asselain B, et al. A new ${ }^{123}$ I-MIBG whole body scan scoring method: application to the prediction of the response of metastases to induction chemotherapy in stage IV neuroblastoma. Eur J Cancer. 1995; 31A:256-261.

31. Messina JA, Cheng SC, Franc B, et al. Evaluation of semi-quantitative scoring system for metaiodobenzylguanidine (mIBG) scans in patients with relapsed neuroblastoma. Pediatr Blood Cancer. 2006;47:865-874.

32. Radovic B, Artiko V, Sobic-Saranovic D, et al. Evaluation of the SIOPEN semiquantitative scoring system in planar simpatico-adrenal MIBG scintigraphy in children with neuroblastoma. Neoplasma. 2015;62:449-455.

33. Lewington V, Lambert B, Poetschger U, et al. ${ }^{123} \mathrm{I}-\mathrm{mIBG}$ scintigraphy in neuroblastoma: development of a SIOPEN semi-quantitative reporting method by an international panel. Eur J Nucl Med Mol Imaging. 2017;44:234-241.

34. Yanik GA, Parisi MT, Shulkin BL, et al. Semiquantitative mIBG scoring as a prognostic indicator in patients with stage 4 neuroblastoma: a report from the Children's Oncology Group. J Nucl Med. 2013;54:541-548.
35. Taggart DR, Han MM, Quach A, et al. Comparison of iodine-123 metaiodobenzylguanidine (MIBG) scan and $\left[{ }^{18} \mathrm{~F}\right]$ fluorodeoxyglucose positron emission tomography to evaluate response after iodine-131 MIBG therapy for relapsed neuroblastoma. J Clin Oncol. 2009;27:5343-5349.

36. Matthay KK, Quach A, Huberty J, et al. Iodine-131-metaiodobenzylguanidine double infusion with autologous stem-cell rescue for neuroblastoma: a New Approaches to Neuroblastoma Therapy phase I study. J Clin Oncol. 2009;27: 1020-1025.

37. Quint LE, Glazer GM, Francis IR, Shapiro B, Chenevert TL. Pheochromocytoma and paraganglioma: comparison of MR imaging with CT and I-131 MIBG scintigraphy. Radiology. 1987;165:89-93.

38. Eisenhofer G. The role of neuronal and extraneuronal plasma membrane transporters in the inactivation of peripheral catecholamines. Pharmacol Ther. 2001;91: $35-62$.

39. van der Harst E, de Herder WW, Bruining HA, et al. [ $\left.{ }^{123} I\right]$ metaiodobenzylguanidine and $\left[{ }^{111} \mathrm{In}\right]$ octreotide uptake in benign and malignant pheochromocytomas. J Clin Endocrinol Metab. 2001;86:685-693.

40. Bhatia KS, Ismail MM, Sahdev A, et al. ${ }^{123}$ I-metaiodobenzylguanidine (MIBG) scintigraphy for the detection of adrenal and extra-adrenal phaeochromocytomas: CT and MRI correlation. Clin Endocrinol (Oxf). 2008;69: 181-188.

41. Kaji P, Carrasquillo JA, Linehan WM, et al. The role of $6-\left[{ }^{18} \mathrm{~F}\right]$ fluorodopamine positron emission tomography in the localization of adrenal pheochromocytoma associated with von Hippel-Lindau syndrome. Eur J Endocrinol. 2007;156: $483-487$.

42. Wiseman GA, Pacak K, O'Dorisio M, et al. Usefulness of ${ }^{123}$ I-MIBG scintigraphy in the evaluation of patients with known or suspected primary or metastatic pheochromocytoma or paraganglioma: results from a prospective multicenter trial. J Nucl Med. 2009;50:1448-1454.

43. Cecchin D, Lumachi F, Marzola MC, et al. A meta-iodobenzylguanidine scintigraphic scoring system increases accuracy in the diagnostic management of pheochromocytoma. Endocr Relat Cancer. 2006;13:525-533.

44. Fischer M, Kamanabroo D, Sonderkamp H, Proske T. Scintigraphic imaging of carcinoid tumours with ${ }^{131}$ I-metaiodobenzylguanidine [letter]. Lancet. 1984;2:165.

45. Feldman JM, Blinder RA, Lucas KJ, Coleman RE. Iodine-131 metaiodobenzylguanidine scintigraphy of carcinoid tumors. J Nucl Med. 1986;27:1691-1696.

46. Hanson MW, Feldman JM, Blinder RA, Moore JO, Coleman RE. Carcinoid tumors: iodine-131 MIBG scintigraphy. Radiology. 1989;172:699703.

47. Watanabe S, Hanaoka H, Liang JX, Iida Y, Endo K, Ishioka NS. PET imaging of norepinephrine transporter-expressing tumors using ${ }^{76} \mathrm{Br}$-meta-bromobenzylguanidine. J Nucl Med. 2010;51:1472-1479.

48. Cistaro A, Quartuccio N, Caobelli F, et al. ${ }^{124}$ I-MIBG: a new promising positronemitting radiopharmaceutical for the evaluation of neuroblastoma. Nucl Med Rev Cent East Eur. 2015;18:102-106.

49. Hartung-Knemeyer V, Rosenbaum-Krumme S, Buchbender C, et al. Malignant pheochromocytoma imaging with $\left[{ }^{124} \mathrm{I}\right] \mathrm{mIBG}$ PET/MR. J Clin Endocrinol Metab. 2012;97:3833-3834.

50. Vaidyanathan G, Affleck DJ, Zalutsky MR. No-carrier-added (4-fluoro-3-[ $\left.{ }^{131} \mathrm{I}\right]$ iodobenzyl)guanidine and (3-[ $\left.{ }^{211} \mathrm{At}\right]$ astato-4-fluorobenzyl)guanidine. Bioconjug Chem. 1996;7:102-107.

51. Suh M, Park HJ, Choi HS, So Y, Lee BC, Lee WW. Case report of PET/CT imaging of a patient with neuroblastoma using ${ }^{18}$ F-FPBG. Pediatrics. 2014;134: e1731-e1734.

52. Pandit-Taskar N, Zanzonico PB, Staton KD, et al. Biodistribution and dosimetry of (18)F-meta fluorobenzyl guanidine (MFBG): a first-in-human PET-CT imaging study of patients with neuroendocrine malignancies. J Nucl Med. Jul. 13, 2017 [Epub ahead of print].

53. Bonfiglioli R, Nanni C, Martignani C, et al. ${ }^{11} \mathrm{C}$-mHED for PET/CT: principles of synthesis, methodology and first clinical applications. Curr Radiopharm. 2014;7:79-83.

54. Franzius C, Hermann K, Weckesser M, et al. Whole-body PET/CT with ${ }^{11} \mathrm{C}$ meta-hydroxyephedrine in tumors of the sympathetic nervous system: feasibility study and comparison with ${ }^{123}$ I-MIBG SPECT/CT. J Nucl Med. 2006;47: 1635-1642.

55. Shulkin BL, Wieland DM, Baro ME, et al. PET hydroxyephedrine imaging of neuroblastoma. J Nucl Med. 1996;37:16-21.

56. Mann GN, Link JM, Pham P, et al. $\left[{ }^{11} \mathrm{C}\right]$ metahydroxyephedrine and $\left[{ }^{18} \mathrm{~F}\right]$ fluorodeoxyglucose positron emission tomography improve clinical decision making in suspected pheochromocytoma. Ann Surg Oncol. 2006;13: 187-197.

57. Amara SG. Neurotransmitter transporters: new insights into structure, function and pharmacology. Rev Bras Biol. 1996;56(suppl 1):5-19. 
58. Ding YS, Fowler JS, Gatley SJ, Dewey SL, Wolf AP, Schlyer DJ. Synthesis of high specific activity $6-\left[{ }^{18} \mathrm{~F}\right]$ fluorodopamine for positron emission tomography studies of sympathetic nervous tissue. J Med Chem. 1991;34: 861-863.

59. Deep P, Gjedde A, Cumming P. On the accuracy of an $\left[{ }^{18} \mathrm{~F}\right]$ FDOPA compartmental model: evidence for vesicular storage of $\left[{ }^{18} \mathrm{~F}\right]$ fluorodopamine in vivo. J Neurosci Methods. 1997;76:157-165.

60. Pretze M, Wangler C, Wangler B. 6- $\left[{ }^{18} \mathrm{~F}\right]$ fluoro-L-DOPA: a well-established neurotracer with expanding application spectrum and strongly improved radiosyntheses. Biomed Res Int. 2014;2014:674063.

61. Kuik WJ, Kema IP, Brouwers AH, et al. In vivo biodistribution of no-carrieradded $6-{ }^{18} \mathrm{~F}$-fluoro-3,4-dihydroxy-L-phenylalanine $\left({ }^{18} \mathrm{~F}\right.$-DOPA), produced by a new nucleophilic substitution approach, compared with carrier-added ${ }^{18} \mathrm{~F}$ DOPA, prepared by conventional electrophilic substitution. J Nucl Med. 2015; 56:106-112.

62. Ilias I, Chen CC, Carrasquillo JA, et al. Comparison of $6{ }^{-18} \mathrm{~F}$-fluorodopamine PET with ${ }^{123}$ I-metaiodobenzylguanidine and ${ }^{111}$ In-pentetreotide scintigraphy in localization of nonmetastatic and metastatic pheochromocytoma. J Nucl Med. 2008;49:1613-1619.

63. Kauhanen S, Seppänen M, Ovaska J, et al. The clinical value of $\left[{ }^{18} \mathrm{~F}\right]$ fluorodihydroxyphenylalanine positron emission tomography in primary diagnosis, staging, and restaging of neuroendocrine tumors. Endocr Relat Cancer. 2009; $16: 255-265$

64. Luster M, Karges W, Zeich K, et al. Clinical value of ${ }^{18} \mathrm{~F}$-fluorodihydroxyphenylalanine positron emission tomography/computed tomography $\left({ }^{18} \mathrm{~F}\right.$-DOPA PET/CT) for detecting pheochromocytoma. Eur J Nucl Med Mol Imaging. 2010;37: 484-493.

65. Cuenca-Cuenca JI, Marín-Oyaga VA, Borrego-Dorado I, Navarro-González E, Martos-Martínez JM, Vázquez-Albertino R. ${ }^{123} \mathrm{I}-\mathrm{MIBG},{ }^{18} \mathrm{~F}-\mathrm{DOPA}$ and ${ }^{18} \mathrm{~F}-$ FDG in a patient with MEN2 syndrome and recurrent pheochromocytoma. Rev Esp Med Nucl Imagen Mol. 2013;32:263-265.

66. Marzola MC, Chondrogiannis S, Grassetto G, et al. ${ }^{18} \mathrm{~F}$-DOPA PET/CT in the evaluation of hereditary SDH-deficiency paraganglioma-pheochromocytoma syndromes. Clin Nucl Med. 2014;39:e53-e58.

67. Lopci E, Piccardo A, Nanni C, et al. ${ }^{18} \mathrm{~F}-\mathrm{DOPA}$ PET/CT in neuroblastoma: comparison of conventional imaging with CT/MR. Clin Nucl Med. 2012;37: e73-e78.

68. Piccardo A, Lopci E, Foppiani L, Morana G, Conte M. ${ }^{18}$ F-DOPA PET/CT for assessment of response to induction chemotherapy in a child with high-risk neuroblastoma. Pediatr Radiol. 2014;44:355-361.

69. Piccardo A, Puntoni M, Lopci E, et al. Prognostic value of ${ }^{18} \mathrm{~F}-\mathrm{DOPA}$ PET/CT at the time of recurrence in patients affected by neuroblastoma. Eur J Nucl Med Mol Imaging. 2014;41:1046-1056.

70. Piccardo A, Lopci E, Conte M, et al. Comparison of ${ }^{18} \mathrm{~F}$-dopa PET/CT and ${ }^{123} \mathrm{I}$ MIBG scintigraphy in stage 3 and 4 neuroblastoma: a pilot study. Eur J Nucl Med Mol Imaging. 2012;39:57-71.

71. Wolden SL, Gollamudi SV, Kushner BH, et al. Local control with multimodality therapy for stage 4 neuroblastoma. Int J Radiat Oncol Biol Phys. 2000; 46:969-974.

72. Modak S, Zanzonico P, Carrasquillo JA, et al. Arsenic trioxide as radiation sensitizer for ${ }^{131}$ I-metaiodobenzylguanidine therapy: results of a phase II study. J Nucl Med. 2016;57:231-237.

73. French S, DuBois SG, Horn B, et al. ${ }^{131} \mathrm{I}-\mathrm{MIBG}$ followed by consolidation with busulfan, melphalan and autologous stem cell transplantation for refractory neuroblastoma. Pediatr Blood Cancer. 2013;60:879-884.

74. DuBois SG, Groshen S, Park JR, et al. Phase I study of vorinostat as a radiation sensitizer with ${ }^{131} \mathrm{I}$-metaiodobenzylguanidine ( $\left.{ }^{131} \mathrm{I}-\mathrm{MIBG}\right)$ for patients with relapsed or refractory neuroblastoma. Clin Cancer Res. 2015;21: 2715-2721.

75. DuBois SG, Allen S, Bent M, et al. Phase I/II study of ${ }^{131}$ I-MIBG with vincristine and 5 days of irinotecan for advanced neuroblastoma. $\mathrm{Br} J$ Cancer. 2015;112:644-649.

76. Englaro EE, Gelfand MJ, Harris RE, Smith HS. I-131 MIBG imaging after bone marrow transplantation for neuroblastoma. Radiology. 1992;182:515520 .

77. Mastrangelo S, Tornesello A, Diociaiuti L, et al. Treatment of advanced neuroblastoma: feasibility and therapeutic potential of a novel approach combining 131-I-MIBG and multiple drug chemotherapy. Br J Cancer. 2001;84: 460-464

78. Matthay KK, Tan JC, Villablanca JG, et al. Phase I dose escalation of iodine131-metaiodobenzylguanidine with myeloablative chemotherapy and autologous stem-cell transplantation in refractory neuroblastoma: a New Approaches to Neuroblastoma Therapy Consortium study. J Clin Oncol. 2006;24:500_ 506.
79. Matthay KK, Weiss B, Villablanca JG, et al. Dose escalation study of nocarrier-added ${ }^{131}$ I-metaiodobenzylguanidine for relapsed or refractory neuroblastoma: New Approaches to Neuroblastoma Therapy Consortium trial. J Nucl Med. 2012;53:1155-1163.

80. Matthay KK, Yanik G, Messina J, et al. Phase II study on the effect of disease sites, age, and prior therapy on response to iodine-131-metaiodobenzylguanidine therapy in refractory neuroblastoma. J Clin Oncol. 2007;25: 1054-1060.

81. Treuner J, Klingebiel T, Feine U, et al. Clinical experiences in the treatment of neuroblastoma with ${ }^{131} \mathrm{I}$-metaiodobenzylguanidine. Pediatr Hematol Oncol. 1986;3:205-216.

82. Klingebiel T, Berthold F, Treuner J, et al. Metaiodobenzylguanidine (mIBG) in treatment of 47 patients with neuroblastoma: results of the German Neuroblastoma Trial. Med Pediatr Oncol. 1991;19:84-88.

83. Lashford LS, Lewis IJ, Fielding SL, et al. Phase I/II study of iodine 131 metaiodobenzylguanidine in chemoresistant neuroblastoma: a United Kingdom Children's Cancer Study Group investigation. J Clin Oncol. 1992;10:18891896.

84. DuBois SG, Messina J, Maris JM, et al. Hematologic toxicity of high-dose iodine-131-metaiodobenzylguanidine therapy for advanced neuroblastoma. J Clin Oncol. 2004;22:2452-2460.

85. Matthay KK, DeSantes K, Hasegawa B, et al. Phase I dose escalation of ${ }^{131} \mathrm{I}$ metaiodobenzylguanidine with autologous bone marrow support in refractory neuroblastoma. J Clin Oncol. 1998;16:229-236.

86. Sisson JC, Shapiro B, Hutchinson RJ, et al. Predictors of toxicity in treating patients with neuroblastoma by radiolabeled metaiodobenzylguanidine. Eur $J$ Nucl Med. 1994;21:46-52.

87. Wilson JS, Gains JE, Moroz V, Wheatley K, Gaze MN. A systematic review of ${ }^{131} \mathrm{I}$-meta iodobenzylguanidine molecular radiotherapy for neuroblastoma. Eur J Cancer. 2014;50:801-815.

88. Zhou MJ, Doral MY, DuBois SG, Villablanca JG, Yanik GA, Matthay KK. Different outcomes for relapsed versus refractory neuroblastoma after therapy with ${ }^{131}$ I-metaiodobenzylguanidine ( ${ }^{131} \mathrm{I}$-MIBG). Eur J Cancer. 2015;51:24652472.

89. Bleeker G, Schoot RA, Caron HN, et al. Toxicity of upfront ${ }^{131}$ I-metaiodobenzylguanidine ( $\left.{ }^{131} \mathrm{I}-\mathrm{MIBG}\right)$ therapy in newly diagnosed neuroblastoma patients: a retrospective analysis. Eur J Nucl Med Mol Imaging. 2013;40: 1711-1717.

90. Mastrangelo S, Rufini V, Ruggiero A, Di Giannatale A, Riccardi R. Treatment of advanced neuroblastoma in children over 1 year of age: the critical role of ${ }^{131}$ I-metaiodobenzylguanidine combined with chemotherapy in a rapid induction regimen. Pediatr Blood Cancer. 2011;56:1032-1040.

91. de Kraker J, Hoefnagel KA, Verschuur AC, van Eck B, van Santen HM, Caron HN. Iodine-131-metaiodobenzylguanidine as initial induction therapy in stage 4 neuroblastoma patients over 1 year of age. Eur J Cancer. 2008;44: $551-556$.

92. Kraal KC, Bleeker GM, van Eck-Smit BL, et al. Feasibility, toxicity and response of upfront metaiodobenzylguanidine therapy followed by German Pediatric Oncology Group Neuroblastoma 2004 protocol in newly diagnosed stage 4 neuroblastoma patients. Eur J Cancer. 2017;76:188-196.

93. Streby KA, Shah N, Ranalli MA, Kunkler A, Cripe TP. Nothing but NET: a review of norepinephrine transporter expression and efficacy of ${ }^{131}$ I-mIBG therapy. Pediatr Blood Cancer. 2015;62:5-11.

94. Johnson K, McGlynn B, Saggio J, et al. Safety and efficacy of tandem ${ }^{131} \mathrm{I}-$ metaiodobenzylguanidine infusions in relapsed/refractory neuroblastoma. Pediatr Blood Cancer. 2011;57:1124-1129.

95. Garaventa A, Guerra P, Arrighini A, et al. Treatment of advanced neuroblastoma with I-131 meta-iodobenzylguanidine. Cancer. 1991;67:922-928.

96. Schmidt M, Simon T, Hero B, et al. Is there a benefit of ${ }^{131}$ I-MIBG therapy in the treatment of children with stage 4 neuroblastoma? A retrospective evaluation of The German Neuroblastoma Trial NB97 and implications for The German Neuroblastoma Trial NB2004. Nuklearmedizin. 2006;45:145-151.

97. Hoefnagel CA, Voûte PA, De Kraker J, Valdés Olmos RA. [ $\left.{ }^{131} \Pi\right]$ metaiodobenzylguanidine therapy after conventional therapy for neuroblastoma. J Nucl Biol Med. 1991;35: 202-206.

98. Lumbroso J, Hartmann O, Schlumberger M. Therapeutic use of $\left[{ }^{131} \mathrm{I}\right]$ metaiodobenzylguanidine in neuroblastoma: a phase II study in 26 patients. $\mathrm{J} \mathrm{Nucl}$ Biol Med. 1991;35:220-223.

99. Feldman JM, Frankel N, Coleman RE. Platelet uptake of the pheochromocytomascanning agent meta-iodobenzylguanadine-I-131. Metabolism. 1984;33:397399.

100. Modak S, Pandit-Taskar N, Kushner BH, et al. Transient sialoadenitis: a complication of ${ }^{131} \mathrm{I}$-metaiodobenzylguanidine therapy. Pediatr Blood Cancer. 2008;50: $1271-1273$. 
101. Quach A, Ji L, Mishra V, et al. Thyroid and hepatic function after high-dose ${ }^{131}$ I-metaiodobenzylguanidine $\left({ }^{131} \mathrm{I}-\mathrm{MIBG}\right)$ therapy for neuroblastoma. Pediatr Blood Cancer. 2011;56:191-201.

102. Wong T, Matthay KK, Boscardin WJ, Hawkins RA, Brakeman PR, DuBois SG. Acute changes in blood pressure in patients with neuroblastoma treated with ${ }^{131} \mathrm{I}$-metaiodobenzylguanidine (MIBG). Pediatr Blood Cancer. 2013;60:1424-1430.

103. Huibregtse KE, Vo KT, DuBois SG, et al. Incidence and risk factors for secondary malignancy in patients with neuroblastoma after treatment with ${ }^{131} \mathrm{I}$ metaiodobenzylguanidine. Eur J Cancer. 2016;66:144-152.

104. Garaventa A, Gambini C, Villavecchia G, et al. Second malignancies in children with neuroblastoma after combined treatment with I-131-metaiodobenzylguanidine. Cancer. 2003;97:1332-1338.

105. Dahia PL. Pheochromocytoma and paraganglioma pathogenesis: learning from genetic heterogeneity. Nat Rev Cancer. 2014;14:108-119.

106. Loh KC, Fitzgerald PA, Matthay KK, Yeo PP, Price DC. The treatment of malignant pheochromocytoma with iodine-131 metaiodobenzylguanidine ( $\left.{ }^{131} \mathrm{I}-\mathrm{MIBG}\right)$ : a comprehensive review of 116 reported patients. J Endocrinol Invest. 1997;20:648-658.

107. Castellani MR, Seghezzi S, Chiesa C, et al. ${ }^{131}$ I-MIBG treatment of pheochromocytoma: low versus intermediate activity regimens of therapy. Q J Nucl Med Mol Imaging. 2010;54:100-113.

108. Gonias S, Goldsby R, Matthay KK, et al. Phase II study of high-dose [ $\left.{ }^{131} \mathrm{I}\right]$ metaiodobenzylguanidine therapy for patients with metastatic pheochromocytoma and paraganglioma. J Clin Oncol. 2009;27:4162-4168.

109. Yoshinaga K, Oriuchi N, Wakabayashi H, et al. Effects and safety of ${ }^{131} \mathrm{I}-$ metaiodobenzylguanidine (MIBG) radiotherapy in malignant neuroendocrine tumors: results from a multicenter observational registry. Endocr J. 2014;61: 1171-1180.

110. Carrasquillo JA, Pandit-Taskar N, Chen CC. I-131 metaiodobenzylguanidine therapy of pheochromocytoma and paraganglioma. Semin Nucl Med. 2016;46:203214.

111. Safford SD, Coleman RE, Gockerman JP, et al. Iodine-131 metaiodobenzylguanidine is an effective treatment for malignant pheochromocytoma and paraganglioma. Surgery. 2003;134:956-962.

112. Gedik GK, Hoefnagel CA, Bais E, Olmos RA. ${ }^{131} \mathrm{I}-\mathrm{MIBG}$ therapy in metastatic phaeochromocytoma and paraganglioma. Eur J Nucl Med Mol Imaging. 2008; 35:725-733.

113. Rutherford MA, Rankin AJ, Yates TM, et al. Management of metastatic phaeochromocytoma and paraganglioma: use of iodine-131-meta-iodobenzylguanidine therapy in a tertiary referral centre. QJM. 2015;108:361-368.

114. van Hulsteijn LT, Niemeijer ND, Dekkers OM, Corssmit EP. ${ }^{131}$ I-MIBG therapy for malignant paraganglioma and phaeochromocytoma: systematic review and meta-analysis. Clin Endocrinol (Oxf). 2014;80:487-501.

115. Wakabayashi H, Taki J, Inaki A, et al. Prognostic values of initial responses to low-dose ${ }^{131}$ I-MIBG therapy in patients with malignant pheochromocytoma and paraganglioma. Ann Nucl Med. 2013;27:839-846.

116. Shilkrut M, Bar-Deroma R, Bar-Sela G, Berniger A, Kuten A. Low-dose iodine131 metaiodobenzylguanidine therapy for patients with malignant pheochromocytoma and paraganglioma: single center experience. Am J Clin Oncol. 2010;33: 79-82.

117. Hoefnagel CA, Den Hartog Jager FC, Van Gennip AH, Marcuse HR, Taal BG. Diagnosis and treatment of a carcinoid tumor using iodine-131 meta-iodobenzylguanidine. Clin Nucl Med. 1986;11:150-152.

118. Pathirana AA, Vinjamuri S, Byrne C, Ghaneh P, Vora J, Poston GJ. I-131-MIBG radionuclide therapy is safe and cost-effective in the control of symptoms of the carcinoid syndrome. Eur J Surg Oncol. 2001;27:404-408.

119. Mukherjee JJ, Kaltsas GA, Islam N, et al. Treatment of metastatic carcinoid tumours, phaeochromocytoma, paraganglioma and medullary carcinoma of the thyroid with I-131-meta-iodobenzylguanidine (I-131-mIBG). Clin Endocrinol (Oxf). 2001;55:47-60.

120. Safford SD, Coleman RE, Gockerman JP, et al. Iodine-131 metaiodobenzylguanidine treatment for metastatic carcinoid: results in 98 patients. Cancer. 2004; 101:1987-1993.

121. Vaidyanathan G, Zalutsky MR. No-carrier-added meta-[ $\left.{ }^{123} I\right]$ iodobenzylguanidine: synthesis and preliminary evaluation. Nucl Med Biol. 1995;22:61-64.

122. Barrett JA, Joyal JL, Hillier SM, et al. Comparison of high-specific-activity Ultratrace ${ }^{123} /{ }^{131}$ I-MIBG and carrier-added ${ }^{123 / 131}$ I-MIBG on efficacy, pharmacokinetics, and tissue distribution. Cancer Biother Radiopharm. 2010;25:299-308.

123. Chin BB, Kronauge JF, Femia FJ, et al. Phase-1 clinical trial results of highspecific-activity carrier-free ${ }^{123}$ I-iobenguane. J Nucl Med. 2014;55:765-771.

124. Owens J, Bolster AA, Prosser JE, et al. No-carrier-added I-123-MIBG: an initial clinical study in patients with phaeochromocytoma. Nucl Med Commun. 2000;21:437-440.
125. Kang TI, Brophy P, Hickeson M, et al. Targeted radiotherapy with submyeloablative doses of I-131-MIBG is effective for disease palliation in highly refractory neuroblastoma. J Pediatr Hematol Oncol. 2003;25:769-773.

126. Gaze MN, Chang YC, Flux GD, Mairs RJ, Saran FH, Meller ST. Feasibility of dosimetry-based high-dose I-131-meta-iodobenzylguanidine with topotecan as a radiosensitizer in children with metastatic neuroblastoma. Cancer Biother Radiopharm. 2005;20:195-199.

127. Fielding SL, Flower MA, Ackery DM, Kemshead J, Lashford LS, Lewis IJ. The treatment of resistant neuroblastoma with ${ }^{131} \mathrm{I}$-mIBG: alternative methods of dose prescription. Radiother Oncol. 1992;25:73-76.

128. Fielding SL, Flower MA, Ackery D, Kemshead JT, Lashford LS, Lewis I. Dosimetry of I-131 metaiodobenzylguanidine for treatment of resistant neuroblastoma: results of a UK study. Eur J Nucl Med. 1991;18:308-316.

129. Buckley SE, Saran FH, Gaze MN, et al. Dosimetry for fractionated I-131-mIBG therapies in patients with primary resistant high-risk neuroblastoma: preliminary results. Cancer Biother Radiopharm. 2007;22:105-112.

130. Matthay KK, Panina C, Huberty J, et al. Correlation of tumor and whole-body dosimetry with tumor response and toxicity in refractory neuroblastoma treated with ${ }^{131}$ I-MIBG. J Nucl Med. 2001;42:1713-1721.

131. Trieu M, DuBois SG, Pon E, et al. Impact of whole-body radiation dose on response and toxicity in patients with neuroblastoma after therapy with ${ }^{131} \mathrm{I}$ metaiodobenzylguanidine (MIBG). Pediatr Blood Cancer. 2016;63:436-442.

132. Shapiro B, Sisson JC, Wieland DM, et al. Radiopharmaceutical therapy of malignant pheochromocytoma with I-131 metaiodobenzylguanidine: results from ten years of experience. J Nucl Biol Med. 1991;35:269-276.

133. Coleman RE, Stubbs JB, Barrett JA, de la Guardia M, Lafrance N, Babich JW. Radiation dosimetry, pharmacokinetics, and safety of Ultratrace ${ }^{\mathrm{TM}}$ Iobenguane I-131 in patients with malignant pheochromocytoma/paraganglioma or metastatic carcinoid. Cancer Biother Radiopharm. 2009;24:469-475.

134. Pandit-Taskar N, Zanzonico P, Hilden P, Ostrovnaya I, Carrasquillo JA, Modak S. Assessment of organ dosimetry for planning repeat treatments of high-dose ${ }^{131}$ I-MIBG therapy: ${ }^{123}$ I-MIBG versus posttherapy ${ }^{131}$ I-MIBG imaging. Clin Nucl Med. Jul. 29, 2017 [Epub ahead of print].

135. Lee CL, Wahnishe H, Sayre GA, et al. Radiation dose estimation using preclinical imaging with ${ }^{124}$ I-metaiodobenzylguanidine (MIBG) PET. Med Phys. 2010;37:4861-4867.

136. Seo Y, Gustafson WC, Dannoon SF, et al. Tumor dosimetry using $\left[{ }^{124} \mathrm{I}\right] \mathrm{m}$ iodobenzylguanidine microPET/CT for $\left[{ }^{131} \mathrm{I}\right] \mathrm{m}$-iodobenzylguanidine treatment of neuroblastoma in a murine xenograft model. Mol Imaging Biol. 2012;14: 735-742.

137. Ott RJ, Tait D, Flower MA, Babich JW, Lambrecht RM. Treatment planning for ${ }^{131} \mathrm{I}$-mIBG radiotherapy of neural crest tumours using ${ }^{124} \mathrm{I}$-mIBG positron emission tomography. Br J Radiol. 1992;65:787-791.

138. Vaidyanathan G, Zalutsky MR. 1-(m- $\left[{ }^{211} \mathrm{At}\right]$ astatobenzyl)guanidine: synthesis via astato demetalation and preliminary in vitro and in vivo evaluation. Bioconjug Chem. 1992;3:499-503.

139. Vaidyanathan G, Affleck DJ, Alston KL, et al. A kit method for the high level synthesis of [ ${ }^{211}$ At]MABG. Bioorg Med Chem. 2007;15:3430-3436.

140. Vaidyanathan G, Strickland DK, Zalutsky MR. Meta-[ $\left[{ }^{211}\right.$ At] astatobenzylguanidine: further evaluation of a potential therapeutic agent. Int J Cancer. 1994;57:908-913.

141. Vaidyanathan G, Friedman HS, Keir ST, Zalutsky MR. Evaluation of meta[ ${ }^{211} \mathrm{At}$ ] astatobenzylguanidine in an athymic mouse human neuroblastoma xenograft model. Nucl Med Biol. 1996;23:851-856.

142. Mairs RJ, Fullerton NE, Zalutsky MR, Boyd M. Targeted radiotherapy: microgray doses and the bystander effect. Dose Response. 2007;5:204-213.

143. More SS, Itsara M, Yang X, et al. Vorinostat increases expression of functional norepinephrine transporter in neuroblastoma in vitro and in vivo model systems. Clin Cancer Res. 2011;17:2339-2349.

144. McCluskey AG, Boyd M, Pimlott SL, Babich JW, Gaze MN, Mairs RJ. Experimental treatment of neuroblastoma using $\left[{ }^{131} \mathrm{I}\right]$ meta-iodobenzylguanidine and topotecan in combination. Br J Radiol. 2008;81(special issue):S28-S35.

145. Chiu HW, Lin JH, Chen YA, Ho SY, Wang YJ. Combination treatment with arsenic trioxide and irradiation enhances cell-killing effects in human fibrosarcoma cells in vitro and in vivo through induction of both autophagy and apoptosis. Autophagy. 2010;6:353-365.

146. Armour A, Cunningham SH, Gaze MN, Wheldon TE, Mairs RJ. The effect of cisplatin pretreatment on the accumulation of MIBG by neuroblastoma cells in vitro. Br J Cancer. 1997;75:470-476.

147. McCluskey AG, Mairs RJ, Tesson M, et al. Inhibition of poly(ADP-ribose) polymerase enhances the toxicity of ${ }^{131} \mathrm{I}$-metaiodobenzylguanidine/topotecan combination therapy to cells and xenografts that express the noradrenaline transporter. J Nucl Med. 2012;53:1146-1154.

148. Yanik GA, Villablanca JG, Maris JM, et al. ${ }^{131}$ I-metaiodobenzylguanidine with intensive chemotherapy and autologous stem cell transplantation for high-risk 
neuroblastoma: a New Approaches to Neuroblastoma Therapy (NANT) phase II study. Biol Blood Marrow Transplant. 2015;21:673-681.

149. Averbuch SD, Steakley CS, Young RC, et al. Malignant pheochromocytoma: effective treatment with a combination of cyclophosphamide, vincristine, and dacarbazine. Ann Intern Med. 1988;109:267-273.

150. Sisson JC, Shapiro B, Shulkin BL, Urba S, Zempel S, Spaulding S. Treatment of malignant pheochromocytomas with 131-I metaiodobenzylguanidine and chemotherapy. Am J Clin Oncol. 1999;22:364-370.

151. Makis W, McCann K, McEwan AJ, Sawyer MB. Combined treatment with ${ }^{131} \mathrm{I}-$ MIBG and sunitinib induces remission in a patient with metastatic paraganglioma due to hereditary paraganglioma-pheochromocytoma syndrome from an SDHB mutation. Clin Nucl Med. 2016;41:204-206.

152. Madsen MT, Bushnell DL, Juweid ME, et al. Potential increased tumordose delivery with combined ${ }^{131} \mathrm{I}$-MIBG and ${ }^{90}$ Y-DOTATOC treatment in neuroendocrine tumors: a theoretic model. J Nucl Med. 2006;47:660667.

153. Popp M, Strumpf A, Zöphel K, Stroszczynski C, Kotzerke J. Intraarterial ${ }^{131}$ IMIBG therapy of neuroendocrine tumors with liver metastases. Nuklearmedizin. 2010;49:N2-N3.
154. Brogsitter C, Pinkert J, Bredow J, Kittner T, Kotzerke J. Enhanced tumor uptake in neuroendocrine tumors after intraarterial application of I-131-MIBG. $\mathrm{J} \mathrm{Nucl}$ Med. 2005;46:2112-2116.

155. Altmann A, Kissel M, Zitzmann S, et al. Increased MIBG uptake after transfer of the human norepinephrine transporter gene in rat hepatoma. J Nucl Med. 2003;44:973-980.

156. Anton M, Wagner B, Haubner R, et al. Use of the norepinephrine transporter as a reporter gene for non-invasive imaging of genetically modified cells. J Gene Med. 2004;6:119-126.

157. Buursma AR, Beerens AM, de Vries EF, et al. The human norepinephrine transporter in combination with ${ }^{11} \mathrm{C}$-m-hydroxyephedrine as a reporter gene/ reporter probe for PET of gene therapy. J Nucl Med. 2005;46:2068-2075.

158. Moroz MA, Serganova I, Zanzonico P, et al. Imaging hNET reporter gene expression with ${ }^{124}$ I-MIBG. $J$ Nucl Med. 2007;48:827-836.

159. Brader P, Kelly KJ, Chen N, et al. Imaging a genetically engineered oncolytic vaccinia virus (GLV-1h99) using a human norepinephrine transporter reporter gene. Clin Cancer Res. 2009;15:3791-3801.

160. Moroz MA, Zhang H, Lee J, et al. Comparative analysis of T cell imaging with human nuclear reporter genes. J Nucl Med. 2015;56:1055-1060. 